Xil.

Aus dem k. k. mobilen Epidemiespital Nr. 16 (Kommandant: k. k. R.-A. i. d. R. Dr. Strisower) und dem k. k. bakteriologischen Feldlaboratorium Nr. 53 (Leiter: k. k. O.-A. Dr. Paul Klemperor).

\title{
Zur Klinik und Pathogenese der Ruhr.')
}

(Mit besonderer Berücksichtigung der rektoskopischen Befunde.)

\author{
Von
}

Dr. E. Egan, Dr. P. Klemperer und Dr. R. Strisower.

(Mit 5 Kurven im Text.)

\section{Rektoskopie.}

Dic massenhaft auftretenden ruhrartigen Darmerkrankungen haben seit Kriegsbeginn dem Kliniker wie dem Hygieniker grosse Schwierigkeiten bereitet. Die Frage, ob die Diagnose Ruhr erst durch den Nachweis der spezifischen Erreger oder bereits nach den klinischen Symptomen gestellt werden dürfe, war bald zugunsten des letzteren entschieden, als man erkannt hatte, dass unter den ersehwerenden Verhältnissen des Feldes auch in ganz sicheren, durch die Autopsie bestätigten Ruhrfällen die Bakteriologie so oft versagte. Weit schwieriger, wenn nicht unmöglich, war jedoch die Beantwortung der Frage, ob spezifische Ruhr oder unspezifischer Darmkatarrh, und damit auch die Entscheidung, ob infektiös oder nicht, in jenen so häufigen Fällen, die die klassischen Symptome der Ruhr nicht in klarer Deutlichkeit aufwiesen. Hier blieb es meist dem subjektiven Ermessen des Arztes überlassen, die Krankheit als Ruhr oder bloss als unspezifischen Dickdarmkatarrh aufzufassen. Den Standpunkt, den manche Autoren [Quincke (1), Sternberg (2)] einnahmen, einer Unterscheidung zwischen Dysenterie und symptomatischer Ruhr, war ein Ausweg, der den praktischen hygienischen Bedürfnissen entsprach, dabei aber bewusst das Problem der sicheren Unterscheidung zwischen Ruhr und unspezifisehem Darmkatarrh zurückstellte. Eine der Hauptaufgaben der vorderen Epidemiespitäler ist es, bei diesen so zahlreich eintreffenden Kranken mit möglichster Raschheit und Sicherheit die Differentialdiagnose zwischen Ruhr und unspezifischem Darmkatarrh zu stellen. Da die klinischen Symptome sich des öfteren nicht in voller Ausbildung vorfinden, die bakteriologische Diagnostik zu häufig versagt, die serologische Untersuchung gerade im Anfang der Krankheit nicht sehr viel Erfolg verspricht, zogen wir die Rektoskopie heran, um durch direkte Untersuchung - Besichtigung des erkrankten Organes - zu einer objektiven Kenntnis des Krankheitsprozesses zu gelangen und so vielleicht einen sicheren Anhaltspunkt für die Diagnose zu gewinnen.

1) Anmerkung bei der Korrektur: Vorliegende Arbeit war am 1. September 1918 abgeschiossen und wurde zu diesem Zeitpunkt dem Druek übergeben. Aeussere Gründe verhinderten ihr Erscheinen bisher. 
Diese Methode wurde bereits vielfach von Singer $(3,4,5)$ und Matthes $(6,7)$ bei der Ruhr empfohlen.

Wir haben im Verlaufe des Jahres 1917 und des ersten Halbjahres 1918 sämtliche eingelieferten Kranken mit rubrähnlichen Symptomen der rektoskopischen Untersuchung unterzogen und bedienten uns bei der Untersuchung des Rektoskops nach Foges, verwandten meist den mittleren Tubus (15 cm Länge). Die Untersuchung ist in der Hand des Geübten eine leichte und bereitet dem Kranken keine Schmerzen, geschweige denn, dass sie Gefahren in sich birgt, selbst bei schwerst verändertem Dickdarm. Der Wert der Untersuchung wird vor vornherein dadurch eingeschränkt, dass sie den Einblick nur auf den untersten Teil des Rektums gestattet, erschwert wird sie durch den Mangel des stereoskopischen Sehens, was sich namentlich bei der Erkennung von Niveaudifferenzen oft unangenehm geltend macht. Während der Untersuchung wurde das Sekret der Schleimhaut direkt zwecks bakteriologischer Untersuchung auf Drigalskiplatten ausgestrichen.

Unsere Untersuchungen, deren Ġesun.... . " über 1000 beläuft, erstreckten sich 1. auf Kranke, die alle Symptome der Ruhr in voller Deutlichkeit aufwiesen, 2. auf solche, bei denen bei der Truppe dic Diagnose "Ruhrverdacht" gestellt worden war, die aber zur Zeit der Einlieferung ins Spital nicht das klare Bild der Ruhr darboten. Viele Patienten wurden während der Dauer ihres Spitalsaufenthaltes mehrmals der rektoskopischen Untersuchung zugeführt. Die vorliegenden Ausführungen stützen sich auf die Befunde bei 260 Patienten, die in einem bestimmten Zeitraum ins Spital anfgenommen worden waren und als Ruhrkranke geführt wurden. Ueberblicken wir die beobachteten rektoskopischen Bilder, so ergibt sich von selbst eine Einteilung derselbon in 4 Formen.

In der ersten Form, die wir in 109 Fällen gesehen haben, bietet sich dem Untersucher folgendes Bild:

Die Schleimhaut ist geschwollen, mehr oder weniger stark gerötet, mit reichlicher serös-schleimiger Sekretion. Häufig sieht man auch in der diffus geröteten Schleimhaut punkt- und streifenförmige Blutungen, dic sich nicht wegwischen lassen. Nicht zu verwechseln mit solchen sind frische Blutungen, die beim Einführen des Rektoskops oder beim Abtupfen der besonders leicht verletzbaren Schleimhaut entstehen können. Diesen Befund haben wir sowohl in Fällen mit ausgesprochenen Ruhrsymptomen als auch bei Kranken, bei denen die kurze Dauer und die milden Erscheinungen der Erkrankung eher an einen Darmkatarrh denken liessen. In 43 Fällen wurden in den Abstrichen von der Schleimhaut Bazillen vom Typus der Mannit vergärenden, in 7 der Mannit nicht vergärenden (Shiga Kruse) Dysenterie gefunden. In 30 Fällen ergab dio Agglutination des Krankenserums mit Mannit vergärenden Stämmen ein positives Resultat. In 29 Fällen war sowohl die bakteriologische als auch die serologische Untersuchung negativ. Prozentuell verteilen sich daher die Ergebnisse der bakteriologisch-serologischen Diagnose bei der Form 1 folgendermassen: Bakteriologisch positiv 46 pCt., serologisch positiv 27,5 pCt., negativ 26,5 pCt. 
In 63 Fällen erhoben wir folgenden Befund (Form II):

Die Schleimhaut ist mehr oder weniger stark gerötet, jedoch trocken und glanzlos mit unebener Oberfläche. Durch die Bezeichnung matt, samtartig, grob chagriniert wird der Grad dieser Veränderung der Oberfäche am besten wiedergegeben. Meist fehlt die reichliche Sekretion, es lässt sich nur schwer mit der Oese der zähe, festaufliegende Schleim abstreifen. Diesen Befund erhoben wir gleichfalls bei klinisch sicheren Rubrfällen als auch bei Kranken, bei denen die klinische Diagnosc zwischen Ruhr und Darmkatarrh schwankte, und zwar meist bei solchen, die erst Ende der ersten Krankheitswoche ins Spital eingeliefert worden waren. In mehreren Fällen sahen wir diese Form bei der zweiten Untersuchung von Patienten, deren Befund anfangs der Form I oder den später zu besprechenden Formen III und IV entsprochen hatte.

In 25 Fällen wurden Mannit vergärende, 11 mal Mannit nicht vergärende Dysenteriebazillen gefunden. Die Agglutination mit Mannit vergärenden ergab in 11 Fällen ein positives Resultat. 16 mal blieb dic bakteriologische und serologische Untersuchung negativ. Das ist in Prozenten ausgedrückt: Bakteriologisch positiv 57 pCt., serologisch positiv 17,5 pCt., negativ 25,5 pCt.

In 42 Fällen begegneten wir folgendem Bild (Eorm III):

Beim Einführen des Rektoskops findet man den Tonus des Sphincter ani stark herabgesetzt, ja vollkommen fehlend, das Lumen des Darmes klafft, so dass der Tubus ohne Aufblasung leicht vorgeschoben werden kann. Die meist düsterrot gefärbte, prall geschwollene Schleimhaut weist in den frischesten Fällen kleienförmige weissliche Beläge auf den Schleimhautwulsten auf. Bei stärkerer Ausbreitung entstehen flächenhafte grauweisse, selten graubraune missfarbige Beläge, so dass grössere Bezirkc dor Schleimhaut bedeckt sind, bisweilen ist jedes eingestellte Gesichtsfeld derart verändert. Die Beläge lassen sich bald leicht abstreifen und hinterlassen dann nur oberflächliche Defekte, bald lassen sie sich mit einer starken Oese nur mit Gewalt entfernen, wobei in der Tiefe einc blutende Fläche zur Sicht kommt. Diese Veränderung fanden wir nur bei klinisch sicheren, schweren Ruhrfällen in den ersten Tagen der Erkrankung. Der bakteriologische Nachweis von Dysenteriebazillen gelang in 37 Fällen (17 mal Mannit vergärende Typen, 20 mal Shiga KruscBazillen), die Agglutination mit Mannit vergärenden Stämmen war 5 mal positiv, das ist in Prozenten: Bakteriologisch positiv $88 \mathrm{pCt}$, serologisch positiv 12 pCt., negativ blieb kein Fall.

41 Fälle wiesen Form IV auf: Auch hier fehlt der Tonus des Sphinkters, das prall geschwollene Darmrohr klafft und es entleert sich während der Untersuchung sehr reichlich blutig-schleimig-eitriges Sekret.

Nach Wegwischen des Exsudats sieht man eine dunkelrote, grob granulierte, bisweilen himbeerartig aussehende Fläche, die selbst bei vorsichtigem Abtupfen leicht blutet. Die Kranken, bei denen wir diesen Befund erheben konnten, waren durchwegs klinisch sichere, schwere Ruhrfälle. Ausserdem sahen wir dieses Bild bei sämtlichen Patienten mit dem rektoskopischen Befund der Form III bei Untersuchung in einem späteren Zeitraume ihrer Erkrankung, wobei sich oft Bilder ergaben, die 
einer Kombination von Form III und IV entsprachen. Die bakteriologische Untersuchung ergab folgende Resultate: 16 mal wurden Mannit vergärende Dysenteriebazillen gefunden, 12 mal Shiga Kruse. Die Agglutination mit Mannit vergärenden Stämmen war in 8 Fällen positiv, 5 mal war das Resultat der bakteriologisch-serologischen Untersuchung negativ. Das entspricht folgendem prozentuellen Verhältnis: Bakteriologisch positiv 68,5 pCt., serologisch positiv 19,5 pCt., negativ 12 pCt. Die Kranken mit Form III und IV wurden während der oft monatelangen Spitalsbehandlung mehrere Male rektoskopiert. Wir wollen daher die Befunde beschreiben, die wir im weiteren Verlaufe der Krankheit erbeben konnten.

Form III geht im Verlaufe der zweiten Woche in Form IV über, was wir wohl mit Sicherbeit daraus erschliessen können, dass wir beide Formen, wie schon erwähnt, oft nebeneinander oder nacheinander bei den gleichen Patienten sehen konnten. Nimmt die Erkrankung einen raschen günstigen Verlauf, so sehen wir nach etwa 4 Wochen ein Bild, das bis auf eine sehr reichliche Schleimsekretion fast vollkommen dem Bild der blassen, glatten, glänzenden, normalen Schleimhaut entspricht; schwindet in den weiteren Wochen auch diese Hypersekretion, so erscheint die Schleimhaut ohne jede Veränderung und unterscheidet sich, soweit das Rektoskop die Einsicht gestattet, gar nicht von der gesunden Schleimhaut. Dass in Fällen mit rekrudeszierendem Verlauf recht lange beide Formen nebeneinander bestehen, konnten wir bisweilen beobachten. Einen anderen Befund erhoben wir jedoch in mehreren Fällen mit protrahiertem Verlauf, bei denen die Schleim- und Eiterbeimengungen zum Stuhl monatelang anhielten. Die schweren Veränderungen der Schleimhaut sind mehr oder weniger zurückgegangen, man sieht jedoch auf Druck mit dem Rektoskop an zahlreichen Stellen stecknadelkopf-bis linsengrosse Eiterpfröpfe vordringen, ein Bild, das an die Angina lacunaris erinnert. Bisweilen sieht man auch ausser solchen vordringenden Eiterpfröpfen an anderen Stellen glasige, gallertartige Klümpchen vortreten. Wischt man die Pfröpfe weg, so sieht man bei genauester Beobachtung eine gan\% kleine, höchstens stecknadelkopfgrosse Stelle. Diesen Befund erhoben wir häufig im Heilungsverlauf der Form III und IV, mehrere Male sahen wir jedoch auch Form II kombiniert mit solchen Eiterpfröpfen.

Wenn wir nun die Frage beantworten wollen, inwieweit diese rektoskopischen Befunde die Diagnose Ruhr gestatten, so ist es klar, dass die Formen III und IV ohne weiteres als Ruhr anzusehen sind. Das rektoskopische Bild entspricht ja vollständig dem anatomisch wohlbekannten Bild der Enteritis crouposa und Enteritis ulcerosa, wie wir es von Sektionen akuter und subakuter Dysenterie her kennen. Sublimatvergiftung, Urämie, die auch die gleichen Veränderungen hervorrufen können, kommen für das hier vorliegende Material natürlich nicht in Betracht. Der hobe Prozentsatz der Fälle, in denen der Nachweis ron Dysenteriebazillen gelungen ist, ist ein weiterer Beweis dafür, dass alle Fälle, die diesen rektoskopischen Befund aufweisen, Dysenterie im engeren Sinne sind. Wir können daher Form III als diphtheritische Ruhr, Form IV als ulzerös-eitrige Ruhr bezeichnen. Entsprechen somit die beschriebenen Bilder bei der Rektoskopie vollkommen dem Obduktionsbefund der 
bazillären akuten und subakuten Ruhr, so erinnerten uns die beschriebenen Eiterpfröpfe, die wir wiederholt beobachteten, an Bilder, die wir vom Obduktionstisch als Colitis cystica kennen. Ob es sich bloss um oberflächliche Zystenbildung (Orth) oder um tiefergreifende Drüsenwucherungen (Löhlein) mit folgender Vereiterung handelt, können wir natürlich mangels Obduktionsbefunde in solchen Fällen nicht entscheiden. Besonders bemerkenswert erscheint uns vor allem das häufige Vorkommen dieses Befundes auch in klinisch nicht schweren, doch protrahierten Fällen.

Der Wert der rektoskopischen Untersuchung bei den schweren Ruhrformen besteht also darin, dass wir die tatsächlich vorhandenen schweren Veränderungen des Enddarmes kennen lernen und den Ablauf des Krankheitsprozesses verfolgen können, woraus sich wertvolle Richtlinien für die Klinik and Therapie ergeben; die bakteriologische Diagnostik gewinnt sehr viel durch die Methode des direkten Ausstreichens. Die Diagnose Ruhr hätte in diesen schweren Krankheitsfällen natürlich auch ohne die rektoskopische Untersuchung gestellt werden müssen.

Schwieriger zu entscheiden ist die Frage, inwieweit der Befund der Formen I und II für die Diagnose Ruhr verwertbar ist.

75 pCt. aller Fälle erscheinen durch das Ergebnis der bakteriologischen und serologischen Diagnose als Dysenterie gesichert. Sind wir berechtigt, die restlichen 25 pCt. ütiologisch gleichzustellen und damit auszudrücken, dass alle Fälle mit dem erwähnten rektoskopischen Befund als Dysenterie im engeren Sinne anzusehen sind? Diese Frage glauben wir bejahen zu können, und geben die Sehuld der verhältnismässig geringeren Ausbeute der bakteriologisch-serologisch positiven Befunde der bekannten Unzulänglichkeit dieser Methodik.

Aus äusseren Gründen konnten wir gerade bei den leichten Formen nur einmal die rektoskopische Untersuchung (dadurch auch den direkten Ausstrich auf Drigalskiplatten) vornehmen, wodurch das bakteriologische Resultat beeinträchtigt wurde. Gelang uns doch sogar bei schwerer, diphtheritischer Ruhr des öfteren erst beim dritten oder vierten Ausstrich die Dysenteriebazillen zu züchten. Auch die serologische Methodik versagt nach unserer Erfahrung in 20 pCt. aller Fälle; es ist selbstverständlich, dass gerade die leichten, sehnell verlaufenden Ruhrerkrankungen in diese Zahl fallen.

Wir sind wohl überzeugt, dass eine katarrhalisch - hämorrhagische Entzündung des Dickdarms auch andere bakterielle und chemische Schädlichkeiten hervorrufen können, doch glauben wir diese Befunde hauptsächlich bei der Dysenterie vorzufinden aus folgenden Gründen: Bei Hunderten sicherer Darmkatarrhe, die wir in gleichem Zeitraum behandelten und rektoskopierten, haben wir meist nur eine leichte Rötung mit etwas vermehrter Schleimsekretion beobachten können, bloss in 5 Krankengeschichten ist ein Befund entsprechend der Form II vermerkt; diese Fälle als Darmkatarrh zu führen, bewog uns das Fehlen jeder klinischen Symptome der Ruhr (auch in der Anamnese) und der negative Ausfall der bakteriologisch - serologischen Untersuchung. Drücken wir das hier Gesagte nochmal in Zahlen aus, so ergibt sich: in 75 pCt. aller Fälle mit dem rektoskopischen Befund der akuten katarrhalischen Ruhr waren 
die Dysenteriebazillen die Lrreger, dagegen boten bloss 2 pCt. der sicheren unspezifischen Darmkatarrhe ein ähnliches rektoskopisches Bild.

Aus den angeführten Gründen glauben wir uns berechtigt, diesen rektoskopischen Befund als fast ausschliesslich der Dysenterie angehörig zu betrachten.

Andererseits fanden wir bei ganz vereinzelten Fällen mit nur leichter Rötung der Schleimhaut Dysenteriebazillen und zwar hauptsächlich bei Kranken, die bei der Einlieferung ins Spital keine typischen Ruhrsymptome aufwiesen, jedoch ganz sichere Ruhranamnese gaben. Dies ist eben die Grenze der Leistungsfähigkeit der rektoskopischen Untersuchungsmethode; in diesen Grenzfällen wird einzig und allein die Bakteriologie und Serologie die Diagnose sichern.

Jedenfalls kommen wir durch genaue Sortierung der rektoskopischen Befunde der wirklichen Zahl der Ruhrfälle erheblich näher, als durch die klinische Bearbeitung oder durch die bakteriologisch-serologische Diagnostik allein.

\section{Klinik der Ruhr.}

Die Symptomatologie der Ruhr war schon vor dem Kriege zur Genüge bekannt und wurde durch die vielen Veröffentlichungen während der vier Kriegsjahre noch vielfach ergänzt, so dass es misslich erscheint, ausführlich dieses Thema zu behandeln. Wir bemühten uns in der vorliegenden Arbeit, weniger bekannte oder strittige Fragen auf Grund unseres Materials zu bearbeiten, wollen daher aus der Klinik der Ruhr nur einige uns wichtig erscheinende Punkte herausgreifen.

Die geläufige Einteilung der Ruhr entspricht dem praktischen Bedürfnis, die Prognose in bezug auf die Schwere und Dauer der Erkrankung zu stellen. Die allgemeinste Fassung, wie sie in die Lehrbücher aufgenommen wurde, in akate und chronische Ruhr, erfuhr bei den meisten Autoren eine Erweiterung. Die akute Ruhr wurde nach der Schwere des Krankheitsbildes in leichte, mittelschwere und schwere Form geteilt. In letater Zeit hat Galambos nach dem Symptomenbild noch die choleriforme und hydrämische Dysenterie unterschieden. Wenn wir bei unserem Material (die Kranken wurden meist zwischen dem zweiten und achten Krankheitstag von der Front eingeliefert) versuchten, aus dem Bild bei der Aufnahme die Prognose in bezug auf den weiteren Verlauf zu stellen, so gelang es nur in den allerseltensten Fällen. Am leichtesten war die Beurteilung der schweren Krankheitsformen mit Allgemeinstörungen, wie Fieber, 'Tachykardie, Abmagerung, Appetitlosigkeit mit bedrohlichen Lokalsymptomen, wie unzähligen rein blutigen Stühlen, starken Tenesmen, Spasmen des Sphincter vesicae usw. Es ist selbstverständlich, dass man mit wochen- ja monatelangem Siechtum rechnen musste. Ganz unmöglich war jedoch die Prognose bei scheinbar auch schwer beginnenden Krankheitsformen mit unzähligen blutig-schleimigen Stühlen und hohem Fieber, jedoch ohne sonstige allgemeine Störungen. Zur grössten Ueberraschung sah man des öfteren diese Kranken binnen 10-14 Tagen vollständig genesen. Umgekehrt trotzten scheinbar leichte Erkrankungen mit wenigen Stühlen, denen Eiter und Blut beigemischt war, des öfteren 
jeder Therapie und dauerten wochenlang, bis die tatsächliche Heilung eintrat. Erst die Rektoskopie und die damit gewonnene Einsicht in die pathologisch-anatomischen Veränderungen des erkrankten Dickdarms erlaubte meist, auch nicht immer, die richtige Einschätzung der Schwere der Erkrankung und eine möglichst objektive Einteilung der Dysenterieformen. Folgen wir nun den im vorhergehenden Abschnitte besprochenen rektoskopischen Befunden, so gibt wohl die diphtheritische Entzündung die schlechteste Prognose (Form III). Alle Patienten, bei denen am Anfang die ganze sichtbare Schleimhaut mit fest haftenden grauweissen Belägen bedeckt ist, der ganze Dickdarm wie ein starres Rohr aussieht, ein reichliches blutig-eitriges Exkret sich durch den schlaffen Sphincter ani entleert, bieten ein sehr schweres Krankheitsbild dar. Von Wichtigkeit ist es, zu betonen, dass anscheinend diese schwere pathologische Veränderung des Dickdarms sich ganz akut entwickelt, ohne dass ein leichteres Stadium vorangegangen wäre. Schon am zweiten bis dritten Krankheitstag waren die Veränderungen in ihrem vollen Umfange ausgebildet. Dem entspricht auch meist die schnelle Entwicklung der schweren klinischen Symptome: ständiger, quälender Tenesmus, unzähbare Entleerungen von rein blutigen oder blutig-eitrigen Massen, Erbrechen, hohes Fieber, Tachykardie. Nach den ersten acht Tagen sind gewöhnlich den blutigen Stühlen ganze Schleimhaut- und Fibrinfetzen beigemischt, als Zeichen der Abstossung der diphtheritischen Beläge. Die Schleimhaut imponiert dann im Rektoskop als eine wunde, tief gerötete und geschwollene Fläche mit reichlichem schleimig-eitrig-blutigem Sekret (Form IV). Wegen des mangelnden Appetits und grossen Wasserverlustes verfallen die Patienten und magern stark ab. Die Wasserverarmung ist kenntlich an den tief halonierten Augen im eingefallenen Gesicht, der trockenen Zunge, der trockenen Beschaffenheit der Haut und dem quälenden Durst. Täglich treten Fiebersteigungen auf, die des öfteren septischen Charakter haben; die schwersten Formen jedoch verlaufen afebril mit choleriformen Symptomen. Wir beobachteten zwei ähnliche Fälle. Die Krankengeschichte des einen (Pospisil, s. Nachtrag) sei hier wiedergegeben, da der rektoskopische Befund ${ }_{n}$ Nekrose der Schleimhaut durch die Sektion bestätigt werden konnte. Auch im zweiten Fall handelte es sich um einen ähnlichen anatomischen Befund. Es sei hier betont, dass jede Therapie bei den schwersten Erkrankungsformen versagt.

Tritt nicht in den ersten 14 Tagen unter Zeichen vollkommener Entkräftung und Herzschwäche (ungünstige Zeichen sind ständige Tachykardie und quälender Singultus) der Tod ein, so sieht man in der dritten Woche eine Wendung zum Besseren. In der überwiegenden Anzahl der Fälle waren wir erstaunt über die schnelle Heilungstendenz der so schwer geschädigten Dickdarmschleimhaut. Schon Ende der vierten, im Verlaufe der fünften Krankheitswoche hatte die Schleimhaut fast normales Aussehen ohne Geschwüre. Bloss eine leichte Schwellung und überreichliche Schleimsekretion erinnerten an die schweren Veränderungen. Dementsprechend besserte sich auch der Zustand der Kranken in der dritten Woche. Als erstes gutes Zeichen ist gewöhnlich die Wiederkehr des 
Appetits zu verzeichnen. Die allgemeinen Symptome, wie Tachykardie, Fieber, Prostration und die Lokalsymptome, die zahireichen blutigschleimigen Stühle, Tenesmen schwinden. Der Tonus des Sphinkters nimmt wieder zu, die Entleerungen werden breiig, fäkulent. Die Kranken mit guter Körperkonstitution und Heilungstendenz können in 6-8 Wochen wieder vollkommen hergestellt sein. Bei einer grossen Anzahl von Fällen bleibt jedoch die Schleimhypersekretion und eitrige Beimengungen noch monatelang erhalten. Es handelt sich dabei um einen rektoskopischen Befund, wie wir ihn als protrahierte Form mit Zystenbildung beschrieben haben: leicht granulierte Schleimhaut mit Eiterpfröpfen, die sich aus den erweiterten Krypten auf Druck des Rektoskops entleeren. Es ist selbstverständlich, dass der Prozess verschiedene Ausdehnung und Intensität haben kann, dementsprechend ist das klinische Bild verschieden. Viele Kranke beobachteten wir in diesem Stadium monatelang (bis 8 Monate). Das Allgemeinbefinden war vorzüglich, sie hatten nach der schweren Ruhr $15-20 \mathrm{~kg}$ an Gewicht zugenommen, vertrugen jede Kost, bloss die öfters wiederkehrenden Beimengungen von Schleim und Eiter zum ganz geformten Stuhl zeigten an, dass die Krankheit nicht völlig zur Ausheilung gelangt ist. Da es uns wiederholt gelungen ist, aus dem Schleim Dysenteriebazillen zu kultivieren, so muss man diese Kranken als ohronische Ruhrkranke bezeichnen, trotz des guten Allgemeinbefindens. Tritt die Heilung der geschwürigen Schleimhaut nicht vollkommen ein, bleiben vereinzelte sichtbare Geschwüre zurück, wird noch die Schleimhaut des Zökums mitergriffen, magern die Patienten stark ab, hören die Blut- und Schleimbeimengungen zum diarrhoischen Stuhl eigentlich nie vollkommen auf, dann haben wir das bekannte schwere Bild der chronischen Ruhr vor uns. Die klinischen Bilder sind zur Genüge jedem Spitalsarst an der Front bekannt, wir wollen sie deshalb hier nicht näher beschreiben. Endlich gehört noch in diese Gruppe die von Galambos so genannte hydrämische Ruhr. Es sind dies meist chronische Ruhrfälle, bei denen neben wochenlangen Diarrhoen und Abmagerung eine besondere Neigung zu Oedemen auffällt. Die Wassersucht kann ganz enorme Grade erreichen und zu Aszites, Pleuritis, Anasarka führen. Zwei einschlägige Fälle hat einer von uns schon im Sommer 1916 beschrieben und Obduktionsbefunde gebracht [Strisower (11)], welche die klinischen Befunde bestätigten, dass es sich hierbei weder um eine Komplikation von seiten der Niere noch des Herzens handelt. Als Ursache der Oedeme wurde damals eine stets vorhandene sekundäre Anämie und Läsion der Gefässe angenommen, wie sie Weltmann (12) für die Oedeme der Rekurrenskranken verantwortlich macht. Inzwischen sind viele Arbeiten über Kriegsödeme erschienen [auch über den Zusammenhang der Ruhr mit Oedembildung von Rumpel (13)], die mit gutem Grund eine mangelhafte qualitative Zusammensetzung der Nahrung (Ueberfluss an Kohlenhydraten in breiig-flüssiger Form mit viel Kochsalz zubereitet) zur Erklärung dieser Erscheinung heranziehen. Es wäre möglich, dass auch bei der hydrämischen Ruhr ähnliche Ursachen mitspielen, ist doch die Nahrungsaufnahme durch die Diarrhoen meist schwer beeinträchtigt, ihre Ausnützung mangelhaft, auch wird des öfteren eine einseitige Ernährung 
mit Mehlspeisen und Mehlsuppen vorgezogen. Seitdem wir auch bei der chronischen Ruhr gemischte Kost in entsprechender Form verabreichten, sahen wir die hydrämische Ruhr und die so oft betonte Oedembereitschaft der Ruhrkranken viel seltener. Endlich kann auch als unterstützendes Moment der vorgebrachten Hypothese herangezogen werden, dass gerade die Kriegsgefangenen mit ihrem schlechten Ernährungszustand besonders zur hydrämischen Rubr neigen (s. Rumpel). Bevor wir diesc kurze, fast schlagwortartige Beschreibung dieser schweren Ruhrformen verlassen, soll hier besonders betont werden, dass bakteriologisch sowohl die Mannit vergärenden, als auch nicht vergärenden Stämme als Krankheitserreger gefunden wurden, allerdings waren die Krusebazillen bäufiger als die anderen Typen (s. Rektoskopie).

Wenden wir uns nun den leichtesten Formen der Ruhr zu, so tritt an uns vor allem die Frage der Abgrenzung gegen unspezifische Darmkatarrhe heran. Es handelt sich um Kranke mit wenig oder gar nicht gestörtem Allgemeinbefinden, mit geringen Leibschmerzen, mit 5--6 diarrhoischen Entleerungen im Tag mit wenig Schleim; 2--3 mal beobachtet man blutig-schleimige Stühle. Die Temperatur ist meist gar nicht oder nur am ersten Tag leicht erhöht. Objektiv ist bei den Kranken nichts Abnormes zu finden, meist besteht nur eine leichte Druckempfindlichkeit des Sigmoideums. Rasche, spontane Heilung in 5-6 Tagen ist der gewöhnliche Ausgang. Da auch rektoskopisch meist kein eindeutiger Befund erhoben werden kann - das gewöhnliche Bild ist leicht gerötete Schleimhaut mit etwas vermehrter Schleimsekretion --, so ist die Abgrenzung gegen unspezifische Darmkatarrhe sehr schwierig. Solche Fälle, die im Verlaufe jeder Epidemie in grosser Anzahl auftreten, sind sieher als Ruhr zu bezeichnen, werden sie sporadisch beobachtet, so ist die Diagnose nicht leicht. Die bakteriologischen und serologischen Befunde werden in einer Anzahl der Fälle Klärung bringen.

Ist der rektoskopische Befund eindeutig, findet man das Bild der katarrhalisch-hämorrhagischen Entzündung: gerötete, mässig geschwollene, aufgelockerte Schleimhant, mit reichlicher serös-schleimiger oder serösblutiger Sekretion, dann ist die Zugehörigkeit zur Ruhr sichergestellt. Auch klinisch ganz leicht verlaufende Fälle findet man darunter; meist handelt es sich jedoch um Erkrankungen, die viel stürmischer beginnen. Es werden anfangs sehr zahlreiche blutig-schleimige Stühle unter mässigen Tenesmen entleert. Das Aussehen der Patienten ist blass, die Wangen etwas eingefallen. Die Untersuchung der Organe ergibt meist einen geringen objektiven Befund, die Zunge ist leicht belegt, etwas trocken, die Kreislauforgane normal, Puls wenig beschleunigt, meist der 'Temperatur entsprechend, die in den ersten Tagen erhöht ist, ja manchmal bis 39 und 40 Grad ansteigt. Das Abdomen ist eingesunken, im Unterbauch, besonders in der linken Darmbeingegend druckempfindlich. Die Leukozytenzahl, wir zählten nur in wenigen Fällen, die mit hohem Fieber eingeliefert wurden, fanden wir erhöht bis 24000 . Der weitere Verlauf gestaltet sich versehieden, entsprechend der Ausbreitung der Erkrankung und der Heilungstendenz der Schleimhaut. Auch die ganz stürmisch beginnenden 
Ruhrfälle können überraschend schnell in Heilung übergehen; rnan sieht dann schon nach 3-4 Tagen wieder breigge Stühle, die bei entsprechendor Diät in weiteren 6-8 Tagen normal werden. Die Dauer der Erkrankung schwankt somit zwischen $2-3$ Wochen. Doch ist der so günstige Ausgang nur in einem kleinen Teil der Fälle zu verzeichnen.

Gewöhnlich tritt die Heilung, wenn keine Komplikationen ron seiten des Magens und Dünndarms hinzutreten, in 4-6 Wochen ein. Anders gestaltet sich der Verlauf in den Fällen, in denen die Dickdarmschleimhaut stärker ergriffen erscheint und nicht vollkommen restituiert wird. In der zweiten Woche sieht man die Zeichen eines mehr subchronischen Verlaufes. Die Schleimhaut ist mehr oder weniger granuliert, gerötet; auch hier beobachtet man manchmal erweiterte Krypten, aus denen sich Eiter- und Schleimpfröpfe entleeren. Die Erkrankung hat dann denselben Verlauf, wie die weiter oben beschriebene milde Form der chronischen Ruhr.

Des öfteren wird bei den verschiedenen Formen der Ruhr durch Komplikationen ron seiten des Magens und Dünndarms die Genesung hinausgeschoben. Die Stühle werden in der zweiten bis dritten Woche nicht normal, sondern bleiben dünnbreiig mit Schleimbeimischung in feiner Verteilung und zeigen das bekannte Bild der Gärung oder der Eiweissfäulnis. Dass hierbei die Anazidität eine wichtige Rolle spielt, sieht man des öfteren an den unverdauten Muskelresten. Bei etwa 50 Fällen dieser Gruppe ergab die Magenausheberung in 46 pCt. eine vollkommene Anazidität. Die Entscheidung, ob es sich bei der akuten Ruhr um eine Miterkrankung des Magens und des Dünndarms handelt, oder ob die Disposition zur Ruhr durch die Anazidität und durch gastrogene Störungen gegeben wird [Porges (14)], ist schwor zu fällen. Nach den vielen Befunden von Anazidität, die wir auch bei anderen Erkrankungen nachweisen konnten, wäre die letztere Annahme wahrscheinlicher. Jedenfalls führt die Anazidität und die Miterkrankung des Dünndarms zu langwieriger Rekonvaleszenz.

Die wiederholt ausgeführten Rektoskopien bestätigten die Annahme, dass der Lokalprozess im Dickdarm abgeheilt ist, höchstens findet man eine vermehrte Schleimsekretion. Da wir über keine Sektion in diesem Stadium der Erkrankung verfügen, so kann auch die Frage nicht entschieden werden, ob es sich nur um eine funktionelle Sekretionsstörung des Dünndarms handelt oder ob gröbere anatomische Veränderungen das Substrat des klinischen Bildes abgeben. Dieses Krankheitsbild dürfte der von Kaufmann und Schmidt (15) beschriebenen dyspeptischen Form der chronischen Ruhr entsprechen. Es bleibt dahingestellt, ob bei genauer Fassung des Begriffes Ruhr der Name chronische Ruhr für alle dieso Formen passt oder $o b$ es sich bei einem Teil der Kranken um eine Nachkrankheit in Gefolge der Ruhr handelt, um eine dyspeptische Störung des Magens und Dünndarms. In dieser kurzen Zusammenstellung haben wir versucht, die hauptsächlichen Formen der Ruhr, die wir an unserem Krankenmaterial gesehen haben, herauszuheben und in Einklang mit den erhobenen rektoskopischen Befunden zu bringen. 
Der Vebersieht halber sei eine Rekapitulierung crlaubt:

Akuto Ruhr.

1. Diphtheritische Form:

a) Ausgang in Heilung. Dauer 1-3 Monate, wenn keine Komplikationen eintreten.

b) Ausgang in die leichte Form der chronischen Ruhr. Ohne schwere Allgemeinerscheinungen (Bildung von Zysten und Eiteransammlung in den Krypten).

c) Ausgang in die schwere Form der chronischen Ruhr, die nach dem Vorschlag von Kaufmann und Schmidt chronisch-ulzerös benannt werden soll.

d) Ausgang in den Tod schon im akuten oder subakuten Stadium.

II. Katarrhalisch-entzündliche Form:

a) Ausgang in Heilung, bei der $\alpha$ ) leichtesten Form in 6-14 Tagen, B) mittelschweren Form in 4-6 Wochen.

b) Ausgang in die leichte Form der chronischen Ruhr wie sub Ib.

c) Ausgang in die dyspeptische Form der chronischen Ruhr (auch bei der diphtheritischen Form beobachtet).

Somit würden wir bei der chronischen Ruhr die oben beschriebenen drei Formen unterscheiden; die spastisch-perikolitische Ruhr (Ka ufmann. Schmidt) hatten wir keine Gelegenheit zu beobachten.

Noch einige Worte zur Symptomatologie und den von uns beobachteten Komplikationen der Ruhr. Das Fieber tritt meist am Anfang der Ruhr auf, ausgenommen die leichtesten und schwersten Erkrankungen. Man beobachtet des öfteren $38-40 \mathrm{Grad}$ in den ersten zwei Tagen, dann kehrt die Temperatur zur Norm zurück; bei den diphtheritischen Formen dauert es meist 10-20 Tage, also solange die Schleimhaut noch geschwärig ist. Selten handelt es sich um eine Kontinua (dann ist die Prognose ernst, besonders wenn gleichzeitig ausgesprochene Tachykardie besteht), meist um remittierendes septisches Fieber mit normalen Frühtemperaturen. Sonst sieht man des öfteren im Verlaufe jeder Ruhr unregelmässige Fieberzacken, die wahrscheinlich Retention von Entzündungsprodukten oder Resorption von fiebererzeugenden Substanzen vom erkrankten Darm zur Ursache haben. Aehnlich wie Jakoby (16) beobachteten auch wir in der dritten Woche oft eine Fieberzacke, für die kein Anhaltspunkt zu finden war. Jedenfalls konnte kein Diätfehler, keine Verschlimmerung des Befindens dafür verantwortlich gemacht werden. Seine Hypothese ist nicht von der Hand zu weisen, dass es sich dabei um einen Zusammenhang mit den immunisatorischen Vorgängen im Körper handelt.

Von den vielen Komplikationen, die wir gesehen haben und die allgemein bekannt sind, seien nur die Gelenkserkrankungen hervorgehoben. Leichtere Schmerzen in den Gelenken treten des öfteren bei Kranken, die mit Serum behandelt werden, auf und sind als ein Teil des bekannten Bildes der Serumkrankheit aufzufassen. Viel ernster sind die schweren Gelenkserkrankungen, die mit Schwellung der Gelenke ohne Rötung der Haut einhergehen und mehrere Gelenke gleichzeitig befallen können. Dass 
es sich dabei um andere Erreger, als beim akuten Gelenkrheumatismus handelt, erkennt man an dem vollkommenen Versagen der Salizyltherapie. Leider sind andere Antipyretika und Antianalgetika (Atophan) wie auch die spezifische Therapie (Vakzine) vollkommen unwirksam. Erleichterung bringt bisweilen die physikalische Behandlung (Heissluftbehandlung), doch sind die Erkrankungen sehr hartnäckig und können sich wochen- ja monatelang hinziehen. Da eine Lokalisation der Bakterien in den befallenen Gelenken nach der ganzen Pathogenese der Rubr nicht anzunehmen ist, muss es sich um toxische Schädlichkeiten handeln. Möglicherweise werden wir beim Vertiefen unserer Kenntnisse über Toxizität verschiedener Ruhrstämme eine entsprechende antitoxische aussichtsvolle Therapie finden.

\section{Therapie.}

Wie wir in der Klinik der Ruhr ausgeführt haben, ist es im Aufangsstadium der Krankheit des öfteren recht unsicher vorauszusagen, ob die Erkrankung schwer oder leicht und wie lange ihre Dauer sein wird. Diese Faktoren bedingen die Schwierigkeit der Beurteilung der Wirksamkeit der eingeschlagenen Therapie und involvieren dio Pflicht, neue Mittel nur an sichergestellten, mittelschweren oder schweren Krankheitsfällen auszuprobieren; heilen doch die Leichtkranken bei Bettrube und Diät ohne oder trotz der Therapie.

Die Frage der spezifischen Wirkung des antitoxischen Serums und der Vakzine ist aus den oben genannten Gründen gerade in den letzten Kriegsjahren so viel umstritten worden. Nun ist die Serumtherapic an und für sich nur bei ganz schweren Krankheitsfällen notwendig und so stellten wir uns die Frage: wie wirkt das Serum bei den allerschwersten, diphtheritisch-toxischen Formen der Ruhr? Vorausgeschickt muss werden, dass wir immer $50-60 \mathrm{ccm}$ Kruse- oder polyvalentes Serum (geliefert vom serotherapeutischen Institut in Wien) intramuskulär oder öfters subkutan und zwar nur in den ersten Tagen nach der Einlieferung ins Spital gaben und die Injektionen 3-4 mal wiederholten. Wir müssen da eine zweifache Wirkung des Serums unterscheiden:

1. auf den anatomischen Prozess,

2. auf den Allgemeinzustand.

Ad 1. Eine lokale Wirkung des Serums auf die diphtheritische Entzündung und zwar sowohl des Kruseserums als auch des polyvalenten (bei den durch Mannit vergärende Stämme hervorgerufenen Erkrankungen) kann man nicht konstatieren. Die Abstossung der diphtheritischen Membranen geschieht nicht früher bei spezifischer Behandlung, sondern frühestens erst Ende der ersten, im Verlaufe der zweiten Woche wie bei der Mehrzahl der nicht behandelten Fälle (s. Krankengeschichte Soukota). Möglicherweise wird das Fortschreiten der diphtheritischen Entzündung sowohl in der Ausdehnung als in die Tiefe durch die Wirkung des Serums gehindert. Dies lässt sich nur an einem grossen Krankenmaterial mit viel Obduktionsbefunden entscheiden; vielleicht sprechen dafür die beigegebene Krankengeschichte von Salat, der ohne spezifische Behandlung noch am 41. Krankheitstage diphtheritische Belägo hatte, im Gegen- 
satz dazu zeigte Nebozuk, der mit viel Seruminjektionen behandelt wurde, trotz der schwersten Erkrankung deutliche Heilungstendenz.

Ad 2. Die günstige Wirkung des Kruseserums auf das Allgemeinbefinden ist wohl unverkennbar. Bald nach der Injektion lassen die Schmerzen im Bauch und die T'enesmen nach, die Entleerungen werden seltener, wenn auch ihr Charakter sich nicht ändert, die Temperatur sinkt, mit ihr parallel der frequente Puls. Weniger deutlich und doch von den meisten Patienten angegeben, ist die Besserung des Allgemeinbefindens bei dem Gebrauch des polyvalenten Serums bei sog. atoxischer Ruhr. Auch wir versuchten es hier wiederholt mit normalem Pferdeserum und konnten auch bei dieser Therapie leichte Besserung konstatieren. Es ist möglich, dass das polyvalente Serum nicht starke antitoxische Eigenschaften hat and deswegen beinen besonderen Vorzug vor normalem Serum aufweist; hat doch Pribram (17) nachgewiesen, dass normales Ziegenserum in mässigem Grade gegen die Toxizität der Pseudodysenteriebazillen schützt. Es liegt auch nahe, die manchmal beobachtete günstige Wirkung des polyvalenten Serums in Analogie zu setzen mit dem bei vielen Infektionskrankheiten bestätigten guten Erfolg der unspezifischen Eiweisstherapie. Welche Erklärung auch richtig ist, wichtig bleibt es für den Kliniker, dass auch die sehweren Dysenterieerkrankungen, die durch Mannit vergärende Stämme hervorgerufen sind, manchmal durch polyvalentes Serum in ihrem Allgemeinbefinden günstig zu beeinflussen sind.

Vom Prof. Paltauf beauftragt, versuchten wir die Vakzinetherapie ${ }^{1}$ ) wobei der Gedankengang zugrunde lag, hauptsächlich subakute und subchronische Fälle durch aktive Immunisierung schneller der Heilung zuzuführen, da bekanntlich das Serum nur im Anfangsstadium der Erkrankung wirksam ist und die Besserung nach der Injektion höchstens 2-3 Tage anhält. Es wurde sowohl von der Krusevakzine als auch von der polyvalenten Vakzino (atoxische Stämme allein oder mit toxischen gemischt) $1-3 \mathrm{ccm}$ subkutan oder intramuskulär injiziert. In Uebereinstimmung mit anderen Autoren sahen wir nie nachteilige Folgen dieser Therapie. Es traten gewöhnlich geringe Schmerzen an der Injektionsstelle auf, hie und da eine mässige Rötung der Haut, nie Schwellung oder Fieber. Leider konnten am Krankenbett die theoretischen Voraussetzungen nicht bestätigt werden. Bei subakuten und chronischen Fällen blieb die Vakzinetherapie unwirksam. Dagegen konnte eine gewisse Wirkung der Vakzination bei akuten Fällen beobachtet werden, ähnlich wie sie ausführlich bei der Serumtherapie auseinandergesetzt wurde. Auch da geben die Patienten eine subjektive Besserung an, besonders bei toxischer Ruhr; der lokale Prozess blieb allerdings unbeeinflusst (s. Krankengeschichte von Slavik). Der Vollständigkheit halber sei hier noch erwähnt, dass sowohl bei der Beeinflussung der Bazillenausscheider als auch der Behandlung von Arthritis bei Ruhr die Vakzination versagt hat (s. Krankengeschichte von Fingyoszan). Zusammenfassend kann nach dem oben Gesagten die spezifische Therapie bei der Kruseruhr empfohlen

1) Die Vakzine wurden vom serotherapeutischen Institut in Wien geliefert. 
werden, die durch Vakzination unterstützt wird (s. Krankengesehichto von Soukota). Man darf sich bloss nicht vorstellen, die schon vorhandene diphtheritische Entzündung schnell zur Heilung zu bringen.

Bei der medikamentösen Therapie muss die Behandlung der akuten Ruhr von der chronischen streng getrennt werden. Nach der Erfahrung, die sich auf Hunderte von Fällen stützt, und nach dem Ausprobieren von allen empfohlenen Mitteln, verwenden wir bei ganz frischen, leichten und mittelschweren Fällen (katarrhalisch-hämorrhagische Form) in den ersten 2-3 Tagen, solange der Stuhl aus den Entzündungsprodukten besteht, leichte salinische Abführmittel. Kalomel in kleinen Dosen ist in seiner Wirkung zu unsicher, in grösseren Mengen (über 0,2) direkt nachteilig. So verordnen wir immer Karlsbader Salz oder Magn. sulf. $10-30 \mathrm{~g}$ täglich in kleinen Mengen verteilt. Es wird dadurch die Retention von Eiter und Schleim verbindert; die Bettruhe, Thermophor und Diät tragen zur baldigen Besserung und Abklingen der akuten Symptome bei. Nach 2-3 Tagen, wenn die Stühle fäkulent werden, beginnt dann die lokale Therapie. Meist verwenden wir lauwarme Einläufe mit Zusatz von Tannin in sehr geringer Konzentration (etwa $0,5 \mathrm{~g}$ in 300 bis $400 \mathrm{cem}$ Wasser) oder Bismut. subnitr. Gleichzeitig bekommt der Patient per os nach dem Vorsehlag von Ziemann Bismut. subnitr. (6-10 mal täglich $0,3-0,5$ täglich).

In weiteren 5-6 Tagen erreicht man bei den Kranken 3-4 breiige Stühle, denen nunmehr selten und wenig Eiter beigemiseht ist. Tritt keine Komplikation hinzu (Anazidität, Dünndarmkatarrh, spastische Obstipation), so genügt die hier skizzierte Behandlung und man erreicht bei sachgemässer diätetischer Therapie in weiteren 2-3 Wochen Heilung. Leider ist ein so glatter Verlauf nur in einem Drittel der ins Spital abgegebenen Fälle zu gewärtigen. In einer Anzahl von Fällen sieht man trotz sorgfältiger Behandlung diese Krankheitsform nieht vollkommen ausheilen, sondern in die Form IIb ausgehen (s. Klinik der Ruhr). Gegen diese Veränderungen der Schleimhaut ist die Therapie ziemlich machtlos. Sowohl die Vakzinetherapie, als auch die lokalen Eingriffe, Spülungen mit Bismut. subnitr., Zine. sulf., Tierkohle, Tannin, Jodoform, Kalium hypermangan., erweisen sich ziemlich wirkungslos. Man gewinnt den Eindruck, dass Einläufe mit Argent. nitr. (in geringer Konzentration, höchstens $1 / 4$ pCt.), 2-3 mal wöchentlich verabreicht, noch am besten die Heilungstendenz des Körpers unterstützen. Der Allgemeinzustand der Kranken ist sonst recht gut, sie nehmen an Gewicht zu, bloss wegen dor aus den Schleimbeimengungen des öfteren gezüchteten Dysenteriebazillen muss man sie oft monatelang noch in Behandlung behalten.

Die häufigste Ursache einer lang andauernden Diarrhoe nach Ablauf der akuten Ruhr ist die Anazidität und der komplizierende Dünndarmkatarrh. In diesen Fällen ist Azidolpepsin, eventuell auch Pankreon das wichtigste Rüstzeug unserer Ruhrtherapie, der Dünndarmkatarrh muss nach den bekannten Prinzipien behandelt werden. Des öfteren treten infolge einer spastischen Obstipation feste Stühle auf, die die noch nicht abgeheilte Dickdarmschleimhaut reizen. Bei solchen Ruhrkranken wird neben leichten Abführmitteln Atropin mit gutem Erfolg angewendet, 
Zur Behandlung der sehweren diphtheritischen Entzündung seicn nur wenige Leitsätze angeführt: Serum oder Vakzine erwiesen sich, wie oben des breiteren auseinandergesetzt wurde, vorteilhaft. Gegen die Herzschwäshe gaben wir Digipurat innerlich oder als Injektion. Tnnere Therapie ist in den ersten Tagen bei dem schwer bedrohlichen Zustand der Patienten vollkommen zwecklos. Die auch in anderen Fällen ohne Erfolg angowandte Bolus- oder Tierkohletherapie verbietet sich bei solchen Kranken infolge des leicht auslösbaren Brechreizes bei Zufuhr so grosser Mengen von Medikamenten von selbst. Im Einklang mit Galambos empfehlen auch wir in den ersten Tagen den Gebrauch von Narkotizis, vorzüglich Opium und Morphium. Nach den ersten 14 Tagen, nach Ablaut der akuten, schweren Symptome, ist die Behandlung analog der bei mittelschweren Formen der Ruhr.

Bevor wir nun die Besprechung der medikamentösen Therapie beenden, soll noch einmal betont werden, dass verschiedenste in der älteren und neuen Literatur angegebene Mittel, per os oder als Klysma (auch als Dauerklysma Enterokliner) verabreicht, gewissenhaft durchgeprüft würden, ohne dass ein besonderer Vorzug irgendeinem der Mittel nachgerühmt werden könnte. Deshalb wurden nur die wenigen Mittel, mit denen man vollkommen gutes Auskommen findet, erwähnt.

Dic chirurgische Behandlung der Ruhr, Zökostomie oder Appendikostomie, wurde 5 mal und zwar bei chronischen Ruhrformen mit Geschwürsbildung und starker Abmagerung versucht, Leider' starben alle Patienten. Bei einem trat eine Pneumonie hinzu, einer kam infolge einer Peritonitis im Anschluss an die Operation ad exitum, die anderen erholten sich nicht mehr trotz der gelungenen Operation, da der Prozess zu weit vorgeschritten war. Doch soll damit nichts gegen die chirurgische Behandlung gesagt sein. Das schwierige Problem bleibt die Indikationsstellung. Wir operierten nur die chronischen Ruhrfälle, die sehr herabgekommen waren und bei denen jede Therapie versagte. Möglicherweise wären die Erfolge günstiger gewesen, wenn man sich rechtzeitig zu dem operativen Eingriff entschlossen hätte. Es eignen sich eben nicht alle Fälle zur Operation. Ausschliessen wird man wohl jede akute Ruhr, auch wenn die Blutung aus dem entzündeten Darm sehr stark ist: wissen wir doch, dass boi Ruhigstellung des Darms durch Opium die Blutungen meist in den ersten Tagen aufhören. Weiters wird man jede chronischdyspeptische Ruhr ausschliessen, auch die ulzerösen Formen, wenn die starke Mitbeteiligung des Dünndarms wahrscheinlich ist. Handelt es sich jedoch sicher um eine chronisch-ulzeröse Form, ist das Allgemeinbefinderı durch den Appetitmangel and die Blutarmut infolge der öfteren Blutbeimengungen zum stuhl gestört, tritt starke Abmagerung infolge der anhaltenden Diarmoen ein, dann soll man nicht mehr lange Zeit mit unnützen therapeutischen Versuchen verlieren, sondern sich bald zur Operation entschliessen, so lange noch die Entkräftung der Patienten nicht zu sehr vorgeschritten ist. Es ist die Zökostomie der Appendikostomie vorzuzichen, da die vollkommene Ruhigstellung des Dickdarms viel mehr Erfolg verspricht, als bloss die Möglichkeit einer Lokaltherapie, wie sie durch die Appendikostomie gegeben ist. 
Für den günstigen Verlauf der Ruhr sind vor allem zwoi Punkte von entscheidender Wichtigkeit:

1. schneller Abschub von der Front in ein gut ausgestattetes Spital,

2. die diätetische Behandlung.

Die sehr geringe Sterblichkeit $(\mathbf{1} \mathrm{pCt}$.) bei unserem Material und dic verhältnismässig kleine Zahl der schweren chronischen Rubrkranken bcziehen wir auf die günstige Lage des Spitales. Kaum $12 \mathrm{~km}$ von der Front entfernt nimmt es die meisten Kranken am 2.-5. Krankheitstage auf. Die Bettruhe und die Diät sind ron ausschlaggebender Wirkung für den weiteren Verlauf der Ruhr. Nur bei schwerstkranken Patienten war das Hungern notwendig, wobei immer noch starker schwarzer Kaffee, Weinsuppe und Tee löffelweise zugeführt wurden. Alle anderen Ruhrkranken bekamen in den ersten Tagen dicke Schleimsuppen mit Ei, Reis-, Gries-, Milch- und leichte Mehlspeise, wie Semmelschmarren, Eierkuchen usw., auch weissen Kaffee, Tee und Zwieback. Sind die akuten Erscheinungen abgelaufen, also nach 3-8 Tagen, dann wird vorerst einmal, dann zweimal Fleisch, geschabt mit Kartofielpüree, Kochsalat passiert, Spinat gereicht; dazu $200 \mathrm{~g}$ Weissbrot geröstet. Meist vertragen die Patienten Fleisch in fein verteilter Form vorzüglich. Dagegen sahen wir des öfteren bei lang andauernder kohlehydratreicher Kost Gärungsstühle auftreten. Im wesentlichen bekommen also die Patienten gemischte Kost in fein verteilter, gut verdaulicher Form. Stufenweise wird dann Käse, Sudfleisch, Braten, Sardinen, gewöhnliches, nicht passiertes Gemüse (Kartoffel, gelbe, rote Rüben usw.) angeordnet. Sind die Stühle längere Zeit schon vollkommen normal, dann wird das Weissbrot zuerst zur Hälfte, wenn dies gut vertragen wird, vollkommen durch das zellulosereiche Schwarz-(Kommis-) Brot ersetzt. Wird die gewöhnliche gemischte Kost ohne Beschwerden verdaut, dann können die Kranken wieder zur Truppe entlassen werden. Zu frühe Entlassung zur Truppe führt gewöhnlich zu einem Rezidiv, wenn nicht zu einem chronischen Stadium der Ruhr.

\section{Epidemiologie.}

Um die Epidemiologie der Ruhr im Kriege zu eriassen, mussten wir den Begriff der Ruhr möglichst scharf umgrenzen. Im Frieden standen die Untersucher abgeschlossenen Epidemien gegenüber. Die Erkenntnis des epidemiologischen Zusammenhanges gestattete es, Erkrankungen, die in der Schwere ihres Verlaufes stark differierten, doch einheitlich aufzufassen. Im Kriege dagegen sahen wir einerseits ausgebreitete Epidemien oder Massenerkrankungen in abgeschlossenen Gruppen, andererseits vorwiegend Einzelerkrankungen aus allen Bereichen der Front, die mit der Diagnose Ruhr in die Epidemiespitäler abgegeben wurden. Die verhältnismässig geringe Arbeitskraft der bakteriologischen Laboratorien brachte es mit sich, dass oft nur in einer geringen Zahl von Fällen der bakteriologische Nachweis der spezifischen Aetiologie erreicht werden konnte. Ausserdem fand gleichzeitig eine grosse Zahl ron Kranken mit der Diagnose Darmkatarrh Aufnahme in die Spitäler, von denen kein kleiner Teil bei der klinischen Beobachtung ein der Ruhr sehr ähnliches Bild 
darbot. Allgemeine Schädlichkeiten alimentärer oder klimatischer Natur, dic unmittelbar vorhergegangen waren, mussten mangels jedes bakteriologischen Befundes als Ursache dieser massenhaften Darmerkrankungen angesehen werden. Diese beiden Umstände, das Versagen der bakteriologischen Diagnostik und die grosse Bedeutung der unspezifischen Schädigungen führten manchen Autoren dazu, unter dem Begriff der „klinischen oder symptomatischen Ruhr" ruhrartige Darmerkrankungen mit ungeklärter Aetiologie allen bakteriologisch oder anatomisch als Dysenterie sichergestellten Krankheitsfällen gegenüberzustellen. Unsere Bemühmug war es, durch Anwendung entsprechender Methoden der Klinik und des Laboratoriums in den Fällen symptomatischer Ruhr zu einer sicheren Diagnose zu kommen, ob es sich um echte Dysenterie oder um unspezifische Darmkatarrhe handelt. Durch die rektoskopische Untersuchung wurden in einem sehr beträchtlichen Teil charakteristische Unterschiede in den Veränderungen des Enddarmes gefunden, wie wir sie früher ausführlich beschrieben haben. Unter diesem derart gesichteten Material könnten wir so häufig spezifische bakteriologische Befunde erheben, dass wir eine Trennung der klinischen Ruhr von der Dysenterie nicht durchführen mussten. Wenn wir somit auch für eine möglichst scharfe Untersuchung zwischen Ruhr and unspezifischem Darmkatarrh eintreten, so sind wir doch von der engen Verknüplung beider überzeugt. Wir kennen das Anwachsen von Darmerkrankungen während des Bewegungskrieges und in den Sommer- und Herbstmonaten. Als Ursachen müssen wir einerseits die Schwierigkeiten der Verpflegung und die mannigfachen einwirkenden Schädlichkeiten (Freilager in grossen Höhen, Genuss von Eisund Schneewasser u. a.), andererseits den reichlichen Genuss von Obst, eventuell klimatische Schädlichkeiten annehmen. So durch allgemeine Noxen bedingt, bereiten die Darmkatarrhe den Boden für die Ausbreitung: der Rubr, indem die Störung der Darmfunktion Gelegenheit zum Haftenbleiben der spezifischen Keime bietet. Infektionsquellen sind ausser gesunden Bazillenträgern besonders häufig jene Personen, deren Erkrankung infolge leichtester Erscheinungen der oberflächlichen Beobachtung entgeht, wie auch Dauerausscheider, die nur golegentlich geringe Krankheitssymptome zeigen. Gerade die letzteren werden bei allen Darmstörungen gefährlich. Solche Einzelbeobachtungen finden wir in der Literatur zahlreich angeführt; anlässlich einer geschlossenen Epidemie in einem Orte des Etappenbereiches hatten wir Gelegenheit, die oben besprochenen Verhältnisse näher kennen zu lernen.

Im September 1917 waren in A. unter den dort dislozierten Truppen viele Darmkatarrhe aufgetreten. In den folgenden Wochen wurden von dort 49 Ruhrkranke ins Epidemiespital eingeliefert, bei denen in 24 Fällen Shiga-Krusebazillen, in 20 Fällen die anderen Typen, oft erst nach mehrmaliger Untersuchung, festgestellt wurden. Zur Bekämpfung der Epidemie wurde angeordnet, die Ruhrverdächtigen sofort ins Epidemiespital abzugeben, alle Soldaten mit Darmkatarrhen zunächst im Feldmarodenhaus zu isolieren. Daselbst wurden sie weiter beobachtet, der Stuhl bakteriologisch untersucht. Unter 70 so isolierten Personen mit leichten Darmerscheinungen wurden 15 herausgefunden, die Ruhrbazillen ausschieden. 
Und zwar boten 6 in den ersten Tagen der Beobachtung unzweifelhafte Ruhrsymptome, die übrigen 9 hingegen wiesen nur ganz leichte Erschejnungen auf, ihr Stuhl zeigte keine Beimengungen von Blut oder Schleim, war in 4 Fällen zur Zeit der Aufnahme ins Marodenhaus überhaupt ganz unverdächtig. Die weitere Beobachtung erfolgt auch bei diesen 15 Fälen im Epidemiespital. Nachdem die Diagnose durch das Resultat der bakteriologischen Untcrsuchung gesichert worden war, erschien der Vergleich besonders wiehtig, wie weit der klinische und rektoskopische Befund mit dem positiven Bazillenbefund übereinstimmen. Klinisch entsprach der Verlauf in 10 Fällen dem einer Rubr, in 5 Fällen hingegen nicht. Durch den rektoskopischen Befund wurden in 14 Fällen jeve Veränderungen gefunden, die uns für die Diagnose Ruhr bestimmend erscheinen, bloss in cinem Falle war die Schleimhaut des Rektums normal. Die Art der Ausbreitung der Krankheit, die im Verlauf von mehreren Wochen erfolgte und sich fast vorwiegend auf einen Truppenkörper beschränkte (die Gesamtzahl der in A. dislozierten Truppen wäre auf etwa 2000 Mann zu veranschlagen), rechtfertigt die Annahme einer Kontaktinfektion. Die grosse Zahl der leicht verlaufenden Fälle trug wohl wesentlich zum langsamen aber stetigen Umsichgreifen der Erkrankungen bei. Fanden wir doch, dass 5 durch die bakteriologische Untersuchung als positiv erkannte Fälle (4 Flexner, 1 Kruse) selbst bei strengster klinischer Beurteilung nur als Darmkatarrhe aufgefasst werden konnten. Bei einem Kranken, bei dem auch die rektoskopische Untersuchung keinen Anhaltspunkt für die Diagnose Ruhr bot, sahen wir uns zu der Annahme gedrängt, dass es sich um einen Bazillenträger bzw. Dauerausscheider handelte. Anamnestische Erhebungen ergaben, dass er 2 Jahre vorher an Ruhr erkrankt gewesen war. Es erscheint selbstverständlich, dass gerade solche Fälle, wenn sie an Darmkatarrhen erkranken, der Umgebung besonders gefährlich werden.

Aehnliche Verhältnisse, wenn auch nicht so übersichtlich, lagen bei der grossen Ruhrepidemie vor, die wir in den Frühjahrs- und Sommermonaten des Jahres 1916 in Tirol zu beobachten Gelegenheit hatten. Bis dahin waren auf diesem Kriegsschauplatze nur wenige Ruhrfälle aufgetreten. Unter den grossen Truppentransporten, die anfangs Februar von anderen Kriegsschauplätzen in 'Tirol eintrafen, fanden sich Formationen, die durch Dysenterie verseucht waren. Auch durch die bakteriologische Durchuntersuchung wurden zahlreiche Bazillenausscheider ermittelt. Im Anschluss an die Offensive kam es zum massenhaften Auftreten von Darmkatarrhen, deren Zahl nach den Beriehten der Salubritätskommission bis über 2000 pro Woche stieg. Gleichzeitig häuften sich die dysenterischen Erkrankungen (bis 300 pro Woche). Sie zeigten alle Bilder von schwerstem Verlauf bis zu den leichtesten Darmerkrankungen, deren Abgrenzung von den unspezifischen Darmkatarrhen klinisch oft nicht durchführbar war. Wir gehen wohl nicht fehl, wenn wir für die Entstehung und Ausbreitung dieser grossen Epidemie die gleichen Verhältnisse annehmen, die wir bei der oben beschriebenen kleinen Epidemie in eng umgrenztem Raume kennen gelernt haben. 
Seither ist die Ruhr in Südtirol nicht zum Erlöschen gekommen. Jedoch tritt sie uns nicht mehr gehäuft zu bestimmten Zeiten oder an bestimmten Orten entgegen, sondern wir sahen im Verlaufe des Jahres 1917 im Abschnitte einer Division 300 Ruhrerkrankungen, die aus allen Teilen des Bereiches stammten und sich ziemlich gleichmässig auf die verschicdenen Monate verteilten. Zum Vergleiche diene, dass die Zahl aller typhösen Erkrankungen im gleichen Zeitraume knapp 100 betrug. In dieser Zahl sind jene Fälle nicht aufgenommen, die zu der oben erwähnten Epidemie in A. gehörten. Zu allen Zeiten, besonders aber in den Wintermonaten, landen wir des öfteren klinisch ganz leicht verlaufende Erkrankungen, deren Diagnose nur durch den rektoskopischen und bakteriologischen Befund ermöglicht wurde. Wir sehen darin die Bestätigung über den Verlauf der Winterruhr, wie ibn Krusse und Lentz beschreiben.

Diese hier skizzierte Art der Verbreitung der Ruhr, sowie die Erfahrungen bei der abgeschlossenen Epidemie in A. beweisen zur Genüge, dass es sich um Kontaktinfektionen handelt, wobei die Häufigkeit der leichten Fälle, die nur zum Teil in Spitälern isoliert werden, die Ansteckungsgefahr wesentlich erhöht. In diesem Zusammenhang erscheint von besonderer Wichtigkeit die Tatsache, dass man durch die rektoskopische Untersuchung noch zu einer Zeit, wo der Kranke bereits als Rekonvaleszent betrachtet werden kann, entzündliche Veränderungen an der Dickdarmschleimhaut erheben kann. In solchen Fällen fanden wir beim direkten Ausstreichen von kleinen Schleimpartikeln noch Dysenteriebazillen, während die 5-6 fache vorhergegangene Untersuchung von Dejekten nach den üblichen Methoden Bazillenfreibeit ergeben hatte. Wir hielten es daher für richtig, die Kranken erst nach der wiederholten rektoskopischen und daran angeschlossenen bakteriologischen Untersuchung aus der Spitalsbehandlung als infektionsfrei zu entlassen.

Für die wirkungsvolle Bekämpfung der wohl in allen Bereichen der Armee im Felde in gleicher Weise auftretenden Ruhr ergibt sich daher die Forderung der Verhütung der Kontaktinfektionen. Diese selbstverständliche, für alle Infektionskrankheiten geltende Massnahme begegnet Schwierigkeiten durch die Unsicherheit der Abgrenzung der leichten Ruhrerkrankungen gegenüber den Darmkatarrhen. Nur durch die möglichst weitgehende Isolierung sämtlicher Darmerkrankungen in Spitälern, wo erst durch eingehende Untersuchung die Unterscheidung durchgeführt werden kann, wäre es erreichbar, die epidemische Ausbreitung der Ruhr bei der Armee im Felde mit Erfolg zu bekämpfen. Wir verkennen nicht die Möglichkeit der Infektion durch Nahrungsmittel oder Wasser, glauben jedoch nach eigenen hier vorgebrachten Erfahrungen, dass sie für die jetzigen Verhältnisse im allgemeinen von untergeordneter Bedeutung ist.

\section{Bakteriologie und Serologie der Ruhr.}

Bevor wir uns zur Besprechung unsererer Erfahrungen in der Bakteriologie und Serologie der Ruhr wenden, erscheint es uns notwendig, unseren Standpunkt gegenüber den verschiedenen Anschauungen, die im Laufe des Krieges über die Frage des Erregers ausgesprochen worden 
sind, klar zu präzisieren. Wir halten uns für berechtigt, zu dieser Frage Stellung zu nehmen, da wir an einem grossen, verschiedenartigen und genau beobachteten Material besonders günstige bakteriologische Resultate erzielen konnten.

Vor Ausbruch des Krieges schien die Aetiologie der Dysenterie völlig klar zu sein und an der Spezifität der Ruhrbazillen als Erreger wurde wohl allgemein nicht mehr gezweifelt. Es erscheint verwunderlich, dass diese durch systematische und genaueste Arbeit von zwei Jahrzehnten befestigte Anschauung gleich in den Anfangsmonaten des Krieges ins Wanken geriet. Durch die geringe Zahl der Bazillenbefunde bei vielen schweren Ruhrerkrankungen wurden die Kliniker gezwungen, die Diagnose Ruhr auch ohne die Hilfe der Bakteriologie zu stellen. Es war naheliegend, dass man mangels ausreichender bakteriologischer Begründung nach anderen Ursachen suchte, die man in den vielfachen alimentären und klimatischen Schädlichkeiten zu finden glaubte. So wurde infolge des Versagens der bakteriologischen Untersuchungsmethoden für die Ruhr, deren schon seit jeher bekannte Unzulänglichkeit erst durch die Massenanforderungen des Krieges deutlich zutage getreten war, der ätiologische Krankheitsbegriff aufgegeben und an seine Stelle trat vielfach der Begriff der "klinischen Ruhr", als deren Ursache unter anderen auch die Dysenteriebazillen angesehen werden. Dieser Begriff der klinisehen Ruhr scheint uns, mag er auch für die praktischen Bedürfnisse einer raschen Einteilung der Kranken ganz förderlich sein, für die notwendige Erkenntnis der Krankheit und ihrer Verbreitung schädlich zu sein. Besonders scharf aber wollen wir uns gegen jene Bemühungen wenden, die vielfach auch von bakteriologischer Seite unternommen werden, gleichsam zur Rehabilitierung der Bakteriologie in der Ruhrtrage neue Erreger zu nominieren. Hypothesen, wie die vom, wild gewordenen Koli", mögen viel Bestechendes an sich haben. Wer aber weiss, wie oft man auf einer Drigalskiplatte unter lauter Koli-Kolonien doch bei genauer Untersuchung einzelne bläuliche Kolonien findet, oder bei häufiger Untersuchung wiederholt negativ befundener Stühle doch einmal zu einem positiven Resultat gelangt, der wird solchen experimentell nicht begründeten Anschauungen vorderhand sehr skeptisch gegenüberstehen. Solange wir unsere Methode der bakteriologischen Ruhrdiagnose als mangelhaft kennen, müssen wir uns vor allem bemühen, diese zu verbessern. Das Gleiche gilt wohl von Befunden, dio Bac. faecalis alcaligenes, Proteus oder Streptokokken ätiologische Bedeutung zuschreiben wollen. Ebenso wie in Dysenteriestühlen haben wir bei Massenuntersuchungen von Gesunden und den vielen Untersuchungen 'Typhus- und Paratyphuskranker wiederholt diese Keime gefunden, oft neben dem spezifischen Erreger, so dass wir uns nicht entschliessen können, ihre Bedeutung in der Aetiologie der Ruhr anzuerkennen. Auch der negative Ausfall von wiederholt unternommenen Agglutinationsversuchen mit dem Serum solcher Kranken, in deren Ausscheidungen die fraglichen Keime bisweilen in Reinkultur gefunden wurden, spricht gegen ihre Natur als Erreger.

Was nun die Frage der ätiologischen Bedeutung der Paratyphus BBazillen bei ruhrartigen Erkrankungen anlangt, so haben wir in mehreren 
Fällen von Darmkatarrhen Paratyphus B-Bazillen im Stuhl gefunden, ohne dass jedoch die rektoskopische Untersuchung die für Ruhr charakteristischen Veränderungen der Dickdarmschleimhaut aufgedeckt hätte. In zwei Fällen schwerer diphtheritischer Entzündung des Darms, in denen bei der ersten Untersuchung aus den Belägen Paratyphus B-Bazillen gezüchtet worden waren, wurden durch weitere Untersuchungen noch Krusebazillen nachgewiesen, so dass in diesen Fällen ëne Mischinfektion angenommen werden musste. In mehreren Fällen von bakteriologisch sichergestellten Paratyphus B-Bazillen-Erkrankungen mit anamnestischen Angaben von blutigen Stühlen im Beginn der Krankheit konnte durch den gleichzeitigen Nachweis von Ruhrbazillen im Stuhl und spezifische Agglutinine im Serum ebenfalls die Annahme ciner Kombination beider Erkrankungen gestützt werden.

Den vorstehenden Ausführungen wollen wir nun die Resultate unserer Untersuchungen ansehliessen. Wir haben von 260 klinisch and rektoskopisch sicheren Ruhrfälen, von denen der grössere Teil zu den leichten Krankheitsformen gehörte, in 151 Fällen, das sind 58 pCt, positive Bazillenbefunde erheben können. Ueber die. Art der Verteilung nach der Schwere des Falles haben wir im Kapitel der Rektoskopie bereits ausführlicher gesprochen. Kurz wiederholend können wir sagen, dass wir bei den schweren Erkrankungen der diphtheritischen und ulzerös-eitrigen Form in $90 \mathrm{pCt}$., in den an Zahl überwiegenden leichten Fällen einer katarrhalischen Entzündung in knapp 50 pCt. positive Resultate erzielen konnten. Die Ursache dieser günstigen Befunde sehen wir erstens darin, dass die Patienten gleich im Beginn ihrer Krankheit zur Untersuchung kamen und zweitens in der Art der Entnahme und des direkten Ausstreichens von Untersuchungsmaterial während der Rektoskopie. Für die erste Begründung, die zwar allgemein bekannt ist, spricht noch der Umstand, dass wir die schlechtesten Resultate in jenen Fällen hatten, die wir sowohl nach ihren Angaben als auch nach dem rektoskopischen Befund als ältere verschleppte Fälle ansehen mussten.

Ausser dem Vorteil der grösseren bakteriologischen Ausbeute konnten wir durch diese Methode der Materialentnahme auch in der Frage der Dauer der Bazillenausscheidung bessere Einsicht gewinnen. Wir haben früher erwähnt, dass wir bei Patienten, die nach dem klinischen Befund und dem Aussehen der Stühle als geheilt angesehen werden konnten, bei der rektoskopischen Untersuchung noch deutliche Zeichen entzündlicher Schleimhautveränderung fanden. Aus dem direkt von der erkrankten Partie entnommenen schleimigen Material züchteten wir oft noch Monate nach dem klinischen Ablauf der Erkrankung Dysenteriebazillen. Besonders die Kruse-Dysenterie zeichnet sich durch ihre lange Dauer aus. Bei den vorgeschriebenen fünfmaligen Stuhluntersuchungen in der Rekonvaleszenz hingegen konnten wir aus den völlig normal aussehenden Dejekten auch in solchen Fällen in der Regel keine Ruhrbazillen mehr herauszüchten, so dass die wenigen positiven Befunde als Zufallstreffor den günstigen Resultaten bèi direkter Auswahl des Untersuchungsmaterials gegenüberstehen. Die Bedeutung dieser langdauernden Ausscheidung, die jedoch bei der gewohnten Art der Untersuchung gar nicht auffallen konnte, für 
die Epidemiologic ist klar verständlich. Es scheint uns daher auch berechtigt, die Bedeutung der Bazillenausscheider höher einzuschätzen, als es allgemein bei der Dysenterie bisher geschieht. Wir fanden bei der periodischen Stuhluntersuchung der Truppenköche in 1 pCt. der Untersuchungen Dysenteriebazillen, wobei wir es dahingestellt sein lassen müssen, ob es sich um gesunde Bazillenträger oder Dauerausscheider nach überstandener Ruhr handelt, denn auch genauestes Befragen der Betroffenen gewährt in dieser Hinsicht keine Sicherheit, da die leichtesten Formen der Ruhr, die so häufig sind, oft kaum beachtet werden. Dic angegebene Zahl von 1 pCt. wurde bei einmaliger Stuhluntersuchung gefunden, weshalb wir sie wohl als den Minimalwert der tatsächlich vorhandenen Bazillenausscheider ansehen müssen. Als weiteren Beweis für die grosse Zahl der Dysenteriebazillenträger führen wir die Beobachtung an, dass wir bei 100 Patienten mit bakteriologiseh sichergestellten typhösen Erkrankungen, die bereits mehrere Wochen im Spital gelegen waren und in dieser Zeit niemals Zeichen einer Ruhrerkrankung geboten hatten, bei den fünfmaligen Rekonvaleszentenuntersuchungen in drei Fällen Dysenteriebazillen feststellen konnten. Der grössere Prozentsatz ist hier wohl nur auf die wiederholte Untersuchung zurückzuführen. Die lange Daver der Ausscheidung bei Kranken und die verhältnismässig grosse Zahl der gesunden oder scheinbar gesunden Bazillenausscheider war uns eine Stütze für unsere oben angeführte Auffassung der endemischen Ausbreitung der Ruhr bei der Armee im Felde, die natürlich jederzeit unter ungünstigen Verhältnissen zu lokaler stärkerer Ausdehnung führen kann.

Bei der weiteren Besprechung unserer bakteriologischen Befunde wollen wir uns möglichst kurz fassen, da sich unsere Untersuchungen stets im Rahmen des Altbekannten hielten und ihren Zweck nur in den Anforderungen der Klinik hatten. Zur Aussaat verwendeten wir den Conradi-Drigalski Lackmus-Nutrose-Milchzuckeragar mit Kristallviolett. Verdächtige Kolonien wurden zur weiteren Untersuchung auf Schrägagarröhrchen überimpft und nach Prüfung auf Beweglichkeit und ihres Verhaltens zu Traubenzucker und Jackmusmolke mit hochwertigem Immunserum identifiziert. Gleichzeitig wurden Kulturen in Mannit-Maltose- und Saccharose-Barsiekowröhrchen angelegt. Während die Trennung der Mannit nicht vergärenden Shiga-Kruse-Bazillen von den Mannit vergärenden 'Typen auch serologisch einwandfrei durchgeführt werden konnte, ergaben sich sehr häufig Unstimmigkeiten in der Einteilung der frisch herausgezüchteten Mannitvergärer nach ihrem serologischen Verhalten und ihrem Spaltungsvermögen der Zuckerarten: Maltose und Saccharose. Eine serologische Einteilung der Mannit vergärenden Dysenteriebazillen nach dem Kruse'schen Schema war bei der grossen Arbeit des bakteriologischen Feldlaboratoriums nicht allgemein durchführbar. Eine Einteilung nach den Formen Y-Flexner und Strong erscheint uns sowohl vom serologischen Standpunkt als auch von dem der chemischen Leistung nicht durchführbar. Da aber für den Kliniker eine Trennung wohl nur zwischen dem Mannit nicht vergärenden Typus und den Mannitvergärern, nicht aber innerhalb der letzteren notwendig erscheint, so fassten wir für die Praxis 
in Uebereinstimmung mit Pribram, Kruse, Hehowerth u. a. dic Mannitvergärer einheitlich zusammen.

Ausser den durch die Agglutination mit Immunserum identifizierten Stämmen begegneten wir nicht selten solchen, die kulturell und morphologisch vollkommen Mannit vergärenden Dysenteriebazillen entsprachen, jedoch dauernd inagglutinabel blieben. Wir tragen keine Bedenken, auch solche Stämme als Dysenteriebazillen zu bezeichnen, zumal wir bei einigen Agglutination mit dem homologen Krankenserum sahen. Es erscheint nur in solchen Fällen notwendig, die kulturellen Eigenschaften, namentlich das Verhalten zu Traubenzucker, mehrmals zu prüfen, damit Verwechselungen mit Bact. coli mit anfangs mangelndem Vergärungsvermögen vermieden werden. Auch der zarte Typus der oberflächlichen Gelatinekolonien ist ein wichtiges Merkmal für die richtige Einreihung.

Die Agglutinationsprüfung des Krankenserums wurde von uns in ausgedehntem Masse angewendet. Wir verwandten dazu nicht zu leicht agglutinable Stämme, deren Agglutinabilität gegenüber Normalserum and Serum nicht Ruhrkranker vorher in vielen Fällen geprült worden war. Wir erhieiten so für unsere Mannit vergärenden Stämme einen Grenzwert, der bei einer Serumverdünnung 1:300 lag, während für den Kruse'schen Bazillus der Wert $1: 100$ betrug. Die Röhrchen kamen zuerst für 2 Stunden in den Brutschrank bei 37 Grad und worden dann über Nacht bei Zimmertemperatur belassen. Das Resultat wurde mit der Lupe abgelesen, wobei jede deutliche Körnchenbildung als positiv angesehen wurde. Einer Unterscheidung zwischen grob- und feinkörniger Agglutination konnten wir uns nicht anschliessen, denn 1. sahen wir die feinkörnige Agglutination bei der Prüfung der meisten Ruhrstümme mit künstlichem, hoehwertigem Immunserum, und 2. sieht man bei der Endtiterbestimmung sehr häufig, dass eine in den schwachen Scrumverdünnungen grobkörnige Agglutination in den stärkeren Verdünnungen feinkörnig wird. Bei einer Agglutination bis zum Endtiter hat man daher den Beweis fiir die Spezifität in der Abstufung der Reaktion von der grobkörnigen bis zur feinkörnigen Ausflockung.

Wir haben zur Orientierung über die Agglutininbildung während der Erkrankung eine Reihe von Untersuchungen durchgeführt, deren Ergebnisse wir hier kurz anführen wollen. Unter 60 Untersuchungen bei bakteriologisch sichergestellten Ruhrfällen war in den ersten 10 'l'agen der Erkrankung der Widal in 34,5 pCt. positiv, in $65,5 \mathrm{pCt}$. negativ. In der zweiten Dekade waren unter 70 Fällen 76 pCt. positive, 24 pCt. negative, unter 50 Fällen der dritten Dekade 56 pCt. positive und 44 pCt. negative Resultate, während in der vierten Dekade nur mehr 17 pCt. positiv und 83 pCt. negativ waren. Die Agglutination in einem späteren Stadium wurden nur bei Patienten durchgefülırt, die noch Zeichen einer Erkrankung boten. Wenn man die durchschnittliche Dauer einer mittelschweren Ruhr mit 5 Wochen veranschlagt, so müssen solche Fälle daher als subchronische Ruhr aufgefasst werden, die aber andere $\Lambda$ gglutinationsresultate gibt, als die akute Erkrankung. Zur Ergänzung prïften wir an einer Reihe von Fällen fortlaufend zu versehiedenen Zeiten den Agglutinationstiter, um uns über die Agglutinationskurve Klarheit zu verschaffen. In 
Uebereinstimmung mit den eben vorgebrachten Ergebnissen sahen wir den Agglutinationstiter im Laufe der ersten zwei Krankheitswochen rasch ansteigen. Er erreicht im Laufe der dritten Woche meist seinen Höhepunkt und fällt in den nächsten Wochen während der Rekonvaleszenz rasch ab.

Abweichend verhalten sich jene Fälle, die nicht rasch abheilen, sondern einen protrahierten Verlauf nehmen, Fälle, wie sie im klinischen Teil als leichte chronische Ruhr beschrieben worden sind. Bei diesen findet man schwankende Agglutinationswerte, so dass man bisweilen erst spät nach wiederholter Untersuchung ein positives Resultat erhält. Analog verhält sich die chronische Ruhr mit Geschwürsbildung. Auch hier sehen wir nach monatelanger Erkrankung hohe Agglutinationswerte, die gerade in solchen Fällen von Colitis ulcerosa, bei denen der Zusammenhang mit einer dysenterischen Erkrankung nicht sicher ist, Klarheit schaffen. Aber auch hier sehen wir oft Schwankungen in der Titerhöhe, so dass gerade bei der chronischen Ruhr die Agglutination häufig zu wiederholen ist.

Die bisher angeführten Tatsachen gelten in gleicher Weise für beide Typen der Dysenteriebazillen. Unterschiede bestehen jedoch in zwei Punkten. Entsprechend der längeren Dauer und dem häufig protrahierten Verlauf der Kruse-Ruhr sahen wir bei dieser die Agglutinationskurve in der Regel langsamer abfallen. Die von den künstlich erzeugten Immunseris her bekannte Mitagglutination der Mannit vergärenden Dysenteriestämme durch Kruseserum besteht auch beim Krankenserum in hohem Masse, so zwar, dass bisweilen der Titer für erstere höher ist als der für den homologen Stamm, umgekehrt jedoch agglutinieren Sera von Kranken, bei denen wir Mannit vergärende Stämme gefunden hatten, niemals Krusebazillen in einer derartigen Höhe, die wir als positiv ansehen mussten. Wir konnten daher die Differentialdiagnose auch durch die Agglutination stellen, wobei wir freilich in einzelnen Fällen, wo die Agglutination sowohl für Mannit nicht vergärende als auch vergärende Stämme hoch war, die Möglichkeit einer Mischinfektion in Betracht ziehen mussten. Den Castellani'schen Versuch konnten wir aus äusseren Gründen nicht durchführen.

Unsere Erfahrungen in der Serologie der Ruhr zusammenfassend, haben wir in $60 \mathrm{pCt}$. ein positives Resultat zu verzeichnen. Hierbei ist zu bemerken, dass die Agglutination häufig nur einmal geprüft wurde, namentlich in jenen Fällen, in denen der bakteriologische Nachweis der Erreger bereits gelungen war. In 57 Fällen, das ist 23 pCt., wurde die klinische, durch den rektoskopischen Befund bestätigte Diagnose durch den positiven Ausfall der Agglutination allein gestütat. In mehreren Hunderten von Fällen, die teils andersartige, namentlich typhöse Erkrankungen, teils Darmkatarrhe betrafen, die klinisch und durch den rektoskopischen Befund nicht als Ruhr angesehen werden konnten, blieb der häufig geprüfte Agglutinationstiter stets unter jenem Werte, den wir für unsere Stämme als positiv angenommen hatten. - Wenn wir somit die Ergebnisse unserer bakteriologischen und serologischen Untersuchungen überblicken, so haben wir bei einem Material von 260 Ruhrfällen in 59,5 pCt. Dysenteriebazillen nachgewiesen, in $21 \mathrm{pCt}$. spezifische Agglu- 
tinine gefunden. Dor verhältnismässig geringe Prozentsatz der negativen Fälle darf wohl nur den bekannten Schwierigkeiten und Mängeln der bakteriologischen Ruhrdiagnose zur Last gelegt werden.

\section{Krankengeschichten.}

Fall Nebozuk. Am 14. 6. plötzlich mit Durchfall und Fieber erkrankt. Bis 30 Stühle tïglich, die mit Blut und Schleim untermischt sind. Bei der Aufnahme bietet der Kranke das Bild einer choleriformen Dysenterie: die Haut ganz trocken, teigig, sichtbare Schleimhäute wenig injiziert. Puls sebr klein, fast unzählbar. Zunge ganz trocken, belegt. Lunge 0. Abdomen hart, eingezogen, überall druck-

Kurve 1.

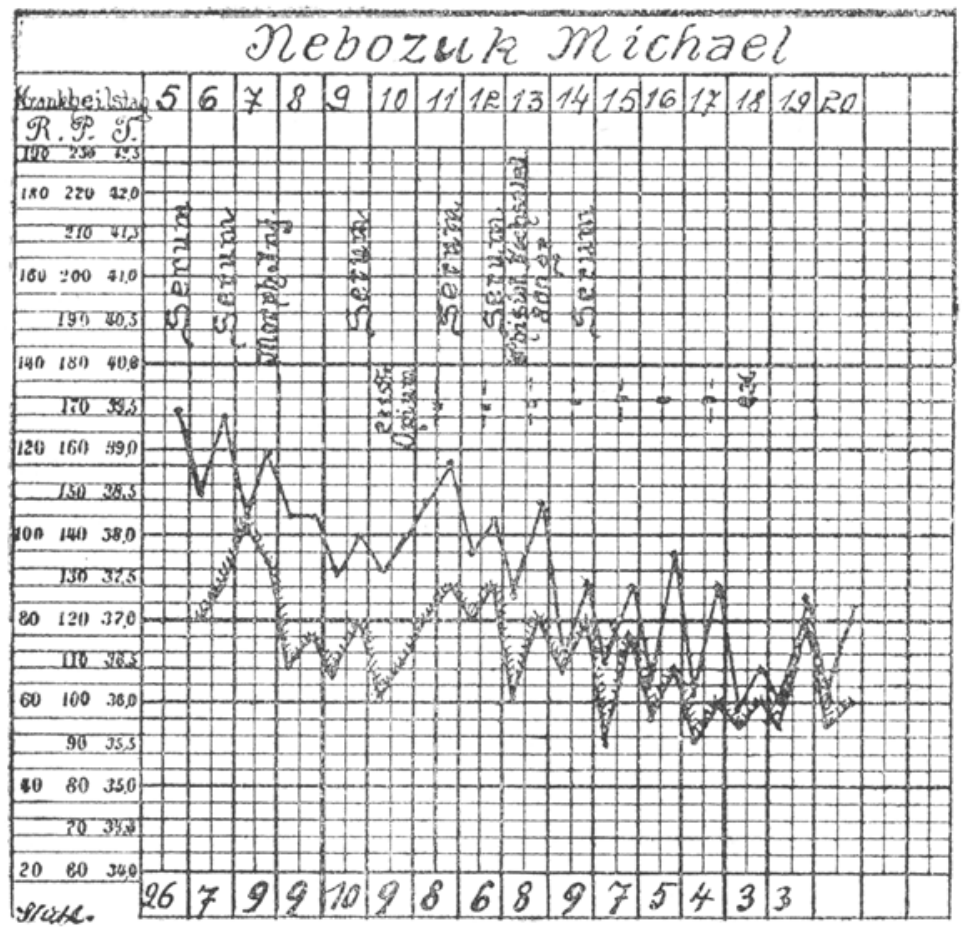

Am 9. Kranlsheitstage lies statt Serum Vakzine.

empfindlich. Die Entleerungen können nicht gehalten werden, bestehen nur aus Fetzen Blut und Eiter.

Rektoskopie: Mangelnder Tonus des Sphinkters. Das Darmrohr steif, weit klaffend, in der ganzen Ausdehnung mit festhaftenden grauweissen Belägen bedeckt.

In den ersten 10 Tagen wird fünfmal 50-60 $\mathrm{cm}$ Kruseserum, einmal Krusevakzine verabreicht (s. Kurve 1), jedesmal tritt subjektive Besserung ein, die jedoch kaum einen halben Tag anhält.

Am 20. 7. Bakteriologischer Befund: Shiga-Kruse. Vom 21. 7. deutliche Bessernng. Patient verlangt selbst mehr zu essen, die Stüble sind schon zeitweise fäkulent, mit wenig Blut untermischt. DerPuls ist kräftig, wenn auch noch beschleunigt.

30. 7. Patient klagt über Husten, Stechen in der Brust.

1. 8. Perkutorisch können lobulärpneumonische Herde nachgewiesen werden. 
2. 8. Zustand verschlimmert sich, der Puls wird wieder klein und schwankt zwischen 100-120. Trotz der Herzmittel keine Besserung der Herzaktion.

Am 3. 8. Exitus. Obduktion: Enteritis ulcerosa et crouposa intestini crassi (Dysent. subacuta). Bronchitis purulenta diffusa bilat. Myodegeneratio cordis gravis. Aus dem Bronchialeiter Influenzabazillen.

Fall Fingyosan, Janos. Anamnese: 18. 11. Seit 8 Tagen Durchfall, anfangs nur flüssige, dann blutig-schleimige Stühle. Starke Koliken.

Status praesens: Die Körperuntersuchung ergibt bis auf ein stark kontrahiertes schmerzhaftes Sigmoidenm negativen Befund. Die Entreerungen bestehen aus Blut, Schleim und Eiter.

Kurve 2.

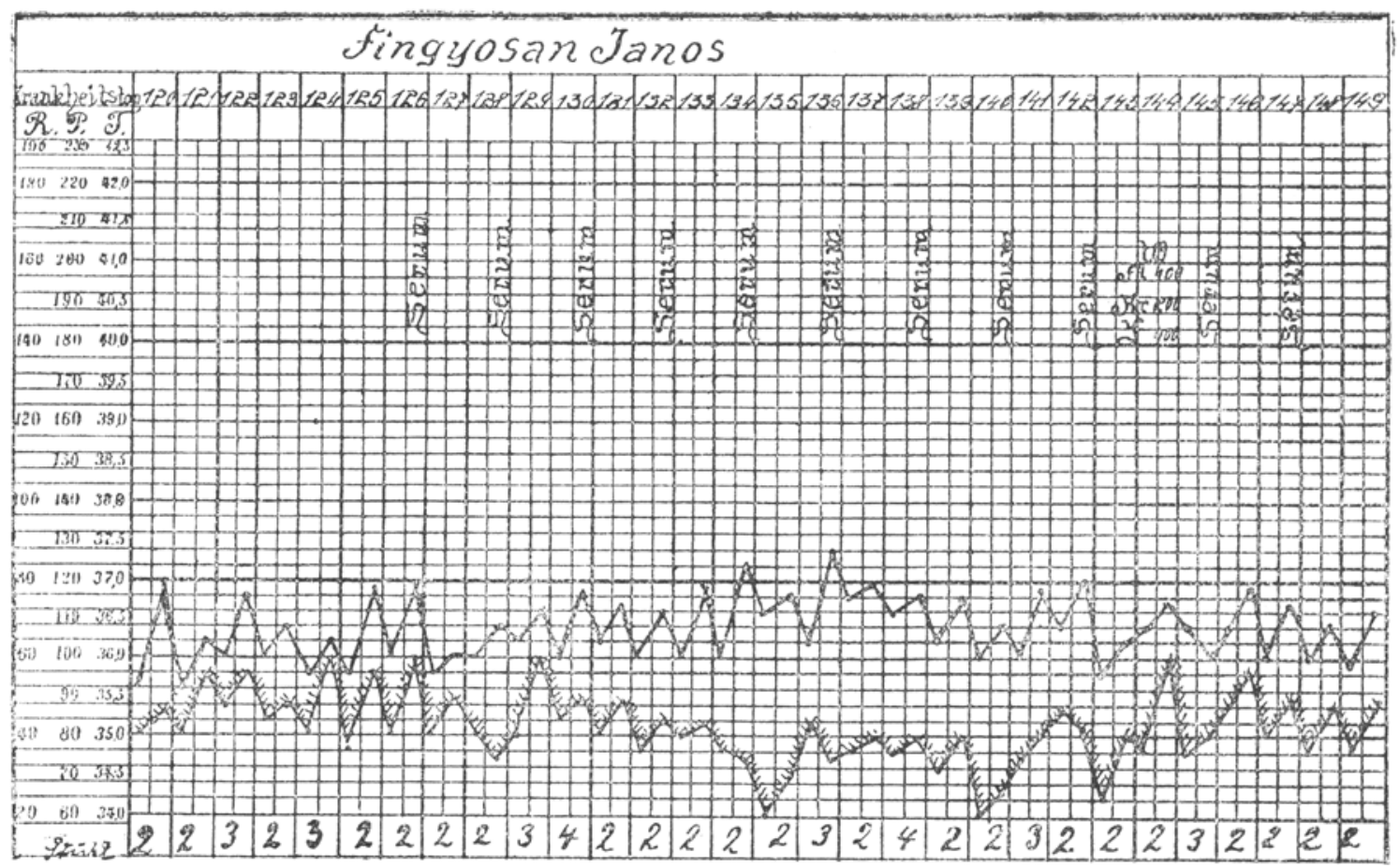

A in 126., 128., 130., 132, 134., 136., 138., 140, 142., 145., 147. Krankheitstage lies statt Serum Vakzine $3 \mathrm{ccm}$.

Rektoskopie: Das Rektoskop wird ohne Widerstand eingeführt. Die Schleimhaut stark uneben, himbeerartig, düsterrot gefärbt, leicht verletzbar, mit reichlicher blutig-eitriger Selrretion (geschwürig-eitrige Ruhr).

Bakteriologische Untersuchung ergibt Krusebazillen.

Der Verlauf gestaltet sich wie bei den meisten mittelschweren Fällen. Nach den ersten 14 Tagen deutliche Besserung; die Stühle werden fäkulent, doch immer mit blutigen und schleimigen Beimengungen.

Am 20. 12. Rektoskopischer Befund: Die loicht gerötete Schleimhant aufgelockert, leicht verletzbar, an einigen Stellen sieht man noch oberflächlich $\mathrm{Gr}_{\theta}$ schwüre. Stuhl geformt, überreichliche Schleimsekretion. Ausstrich des Schleims ergibt wieder Krasebazillen. - Da der Zustand nun chronisch wird und neben gut geformtem Stuhl immer wieder Schleim und Blut entleert wird, wurde im Verlauf der 
nächsten 3 Monate zweimal mit der Vakzinetherapie versucht; das erste Mal wurde Ende Dezember bis anfangs Januar 3 mal Krusevakzine (a $1 \mathrm{ccm}$ ) sublutan, das zweite Mal (Mitte März bis Mitte April) $12 \mathrm{mal} \mathrm{à} 3 \mathrm{ccm}$ injiziert. Eine Besserung des Krankhoitsbildes oder des lokalen Prozesses konnte nicht konstatiert werden, wie wiederholt ausgeführte Rektoskopie ergab. Auch konnten immer wieder Krusebazillen im Schleim nachgewiesen werden. - Der allgemeine Zustand des Patienten war sehr gut, er hat viel Appetit gehabt, hat an Gewicht $10 \mathrm{~kg}$ zugenommen. Nach 8 monatiger Behandlung wurde or als Dauerausscheider abgeschoben.

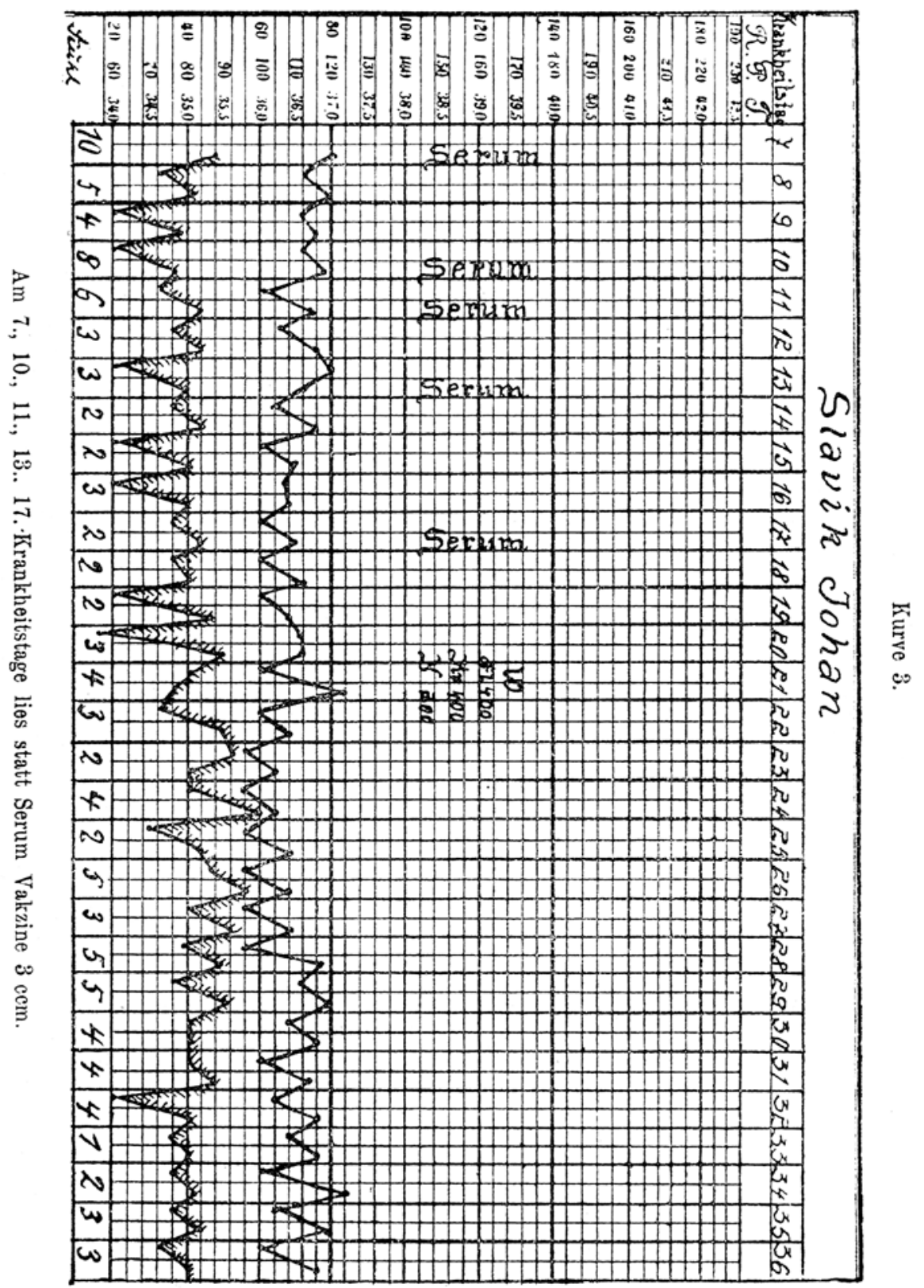


Fall Slavik, Johan. Anamnese am 4. 6.: Erkrankt vor 8 Tagen mit starkem Durchfall. Täglich 10 Stühle mit Blut und Sobleim, die unter Tenesmen abgesetzt werden. 'Temperatur erreicht bis 37,70. Appetit anfangs gering, jetzt gut.

Status praesens: Zunge trocken, weiss belegt. Diffuse Bronchitis. Herz ohne Befund. Abdomen um den Nabel leicht empfindlich. Stuhl blutig, eitrig und schleimig. Urin 0.

4. 6. Rektoskopie: Offenes Darmlumen. Schleimbaut granuliert (oberflächliche Schicht fehlend), leicht blutend, mit eitrig-schleimigem Sekret. Im Ausstrich des Sebleimes wurden bakteriologisch Shiga-Krusebazillen nachgewiesen.

Wie aus der Kurve 3 ersichtlich, besteht die Behandlung in den ersten 14 Tagen neben leichten Abführmitteln aus Injektionen von Krusevakzinen (à 3 ccm subkutan). Die lokale Reaktion bis auf leichte Schmerzhaftigkeit der Impfstelle fehlte. - Schon nach der dritten Injelition am 11. 6. konnte man bemerken, dass der Patient sich wohler fühlte, dass die Anzahl der Stühle bedeutend abgenommen und dass der 'Tenesmus nachgelassen bat. Doch ist der Lokalprozess wenig beeintlusst; so ist noch am 26. 6., also nach 3 Wochen, rektoskopisch folgender Befund erhoben worden: Die Schleimhaut erscheint noch leicht geschwollen, mässig gerötet, auf Druck des Rektoskops entleert sich an vielen Punkten aus der Schleimhaut Eiter. - Die Behandlung wird mit Argent. nitric.-Einläufen und Bismutum subnitricum fortgesetzt.

Erst am 1. 8. konnte der Patient als gebeilt entlassen werden. (Rektoskopischer Befund: normale Schleimhaut.)

Fall Pospisil, Josef. Anamnese: Seit 8 'Tagen krank, unzählige Stühle im Taz, aus Blut und Schleim bestehend. Starke krampfartige Bauchschmerzen. Viel Brechreiz. Nach dem Essen Erbrechen. In den ersten Tagen Fiebersteigung bis 37,50 .

Status praesens am 12. 8: Der Patient macht den Eindruck eines Cholerakranken. Die Wasserverarmung kenntlich an der scblaffen teigigen Haut, deren Falten stehen bleiben, an dem eingefallenen Gesicht, tiefhalonierten Augen. Der Puls klein, fadenförmig, 100. Die Zunge mit dickem braunem Belag belegt, trocken. Lunge normal. Herztöne leise. Bauch eingezogen, stark schmerzhaft bei Druck.

Rektoskopie: Schlaffer Sphinkter. Die Schleimhant teilweise von braunrötlicher Farbe, leicht einreissbar (nekrotiscb), teilweise mit leicht baftenden, woissen Belägen bedeckt. Reichliches blutiges Sekret fliesst ab, dem Fibrinfetzen beigemischt sind.

Therapie: Infusion von $600 \mathrm{ccm}$ physiol. Kochsalzlösung $+80 \mathrm{ccm}$ Serum + Digipurat.

14. 8. Zustand verschlimmert, jede eingenommene Speise wird erbrochen. Unzählige blutige Stühle.

15. 8. Ermüdender Singultus, der nur durch Morphium für wenige Stunden behoben wird. Puls stark beschleunigt, kaum tastbar.

16. 8. Trotz Exzitantien tritt unter Zeichen der Herzsohwäche der Tod ein. Sektionsbefund: Enteritis necroticans intestini crassi totius (Dysenteria acuta). Bronchopneumonia lobul. conf. lobi inf. utr. et partis post. lobi sup. d. T'tbc. chron. apicis pulmonis utr. cum caverna apicis sin. Myodegeneratio cordis. Baliteriologischer Befund: Im Dickdarm Shiga-Kruse.

Fall Soukoto, Franz. Erkrankt am 4. 6. 1918. Täglich bis 30 Stühle, mit T'enesmen, blutig-eitrige Entleerungen. Fieber gering, kein Erbrechen.

Status praesens: Patient zeigt eingefallenes Gesicht, halonierte Augen. Puls klein, regelmässig, schlecht gespannt, 90. Zunge weiss belegt, trocken. Lunge 0 . Herz von normaler Grösse. Herztöne kaum hörbar, Abdomen eingezogen. Unterbauch stark druckempindlich, besonders in der linken Darmbeingrube, Entleerungen aus Blut. Eiter und Schleim bestehend. 
Rektoskopie: Sphinktertonus fehlend, das Darmrohr weit klaffend, dicht besetzt mit graugelben, festhaftenden Belägen. Wo dieselben fehlen, siebt man Geschwüre, mit Eiter belegt. Reichlichos eitrig-blutiges Sekret.

9. 6. Zustand unverändert. $60 \mathrm{ccm}$ Kruseserum intramuskulär. Flüssige Diät (Weinsuppe, starker Bohnenkaffeo, Scbleimsuppe, Kakao).

Am 10. und 11.6. Wiederholung der Therapio. Dio Besserung hielt 24 Stunden an. Patient fühlt sich wohler. Der Puls ist kräftiger. Der Charakter der Stühle unverändert. Nachts Morphiuminjektionen. Kektoskopischer Bofund wio am 8. 6. Baktoriologischer Bofund: Shiga-Kruse.

Kurve 4.

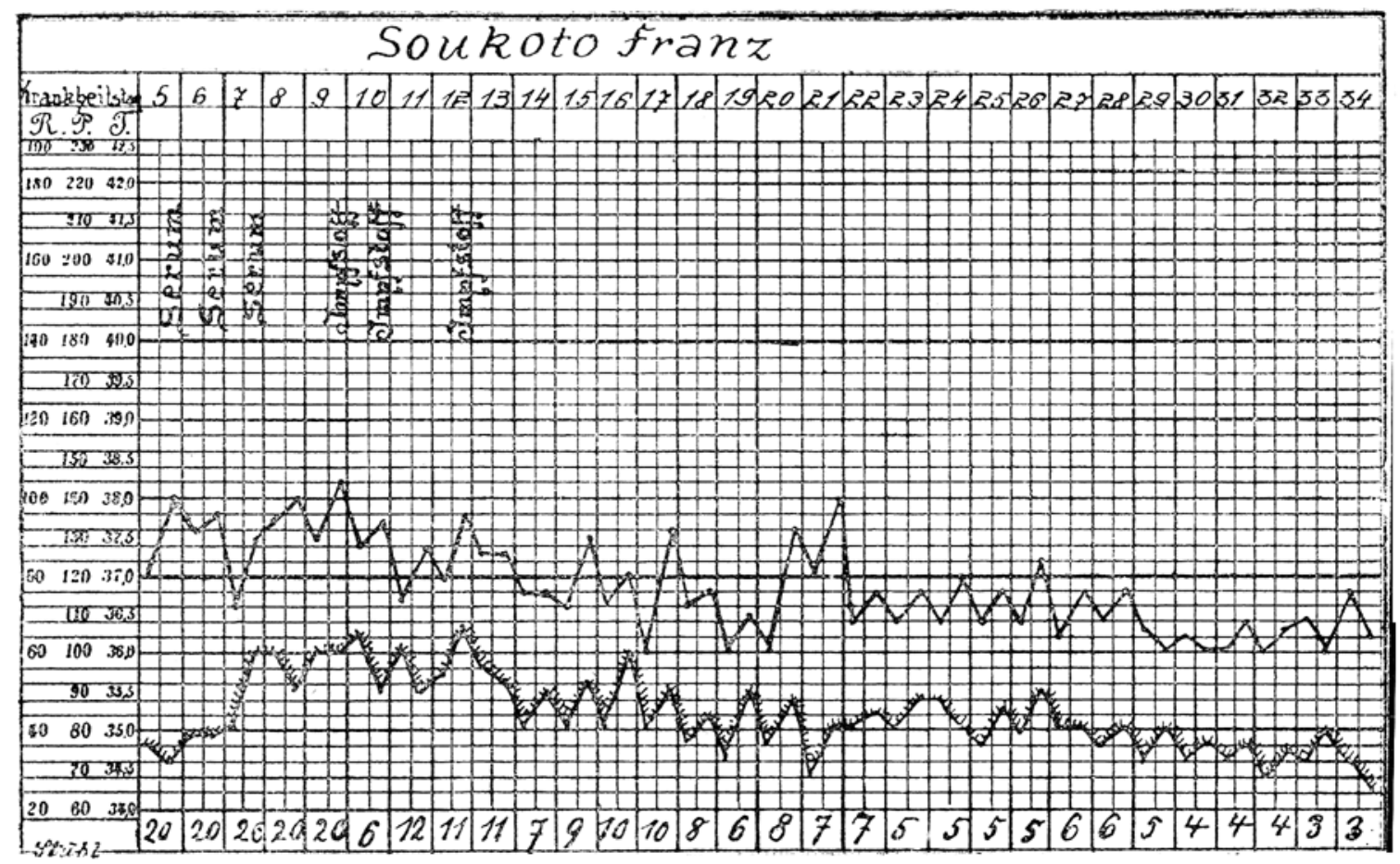

Die.Behandlung am 13.-14. und 16. 6. (ersichtlich aus der Karve 4) besteht in dreimaliger Injektion der Krusevakzine (3 ccm subkutan). Die Impfstelle bleibt reaktionslos. Die Besserung des allgemeinen Befindens wie nach der Seruminjektion.

20.6. Rektoskopie: Granulationsfläche mit eitrigem Sekret, Beläge vollkommen abgestossen. Therapie: Bismuteinläufe und Bismut intern. Reichliche Ernährung: Eierspeise, Schleimsuppe, Omlette, Milchreis, Milchkakao, 1 Weissbrot $(200 \mathrm{~g}), 1$ Zwieback.

21. 6. Schmerzen in beiden Hüftgelenken bei jeder Bewegung, keine Schwellung, keine Rötung. Verordnet: Natrium salicyl. $4 \mathrm{~g}$. Stühle schon fäkulent, mit Schleim untermisobt.

1. 7. Rektoskopie: Schleimhaut noch stark gerötot, mit oberfläoblichen Epitheldefekten (matt), ohne Eitersekretion.

10. 7. Rektoskopie: Schleimhaut glänzend, leicht byperämisch, mit reichlicber Schleimsekretion, keinerlei Narben siohtbar.

Der Appetit des Patienten ist recht gut, es wird jetzt zwoimal täglich gewiegtes Mleisch mit passiertem Gemüse (Spinat-Kartoffeln) und zwei Portionen Weissbrot ver- 
ałłreicht. Der Patient erholt sich sehr schnell in weiteren 8 Tagen, es wird Sudlloisch gat vertragen. Einmal täglich Stuhl breiig-fest.

Am 6. 8. [nach Ueberstehen einer Influenza (am 28. 7. bis 1. 8.)] kann Patient als Rekonvaleszent entlassen werden. Tenosmus.

Fall Salat, Adelbert. Seit 18 Tagen Diarrhoen. Stuhl mit Blut untermischt,

8. 4. Status praesens: Patient sehr stark abgemagert, besonders im Gesicht. Ilautfarbe blass, sichtbare Schleimhäute wenig injiziert. Puls von geringer Spannung,

Kurve 5.

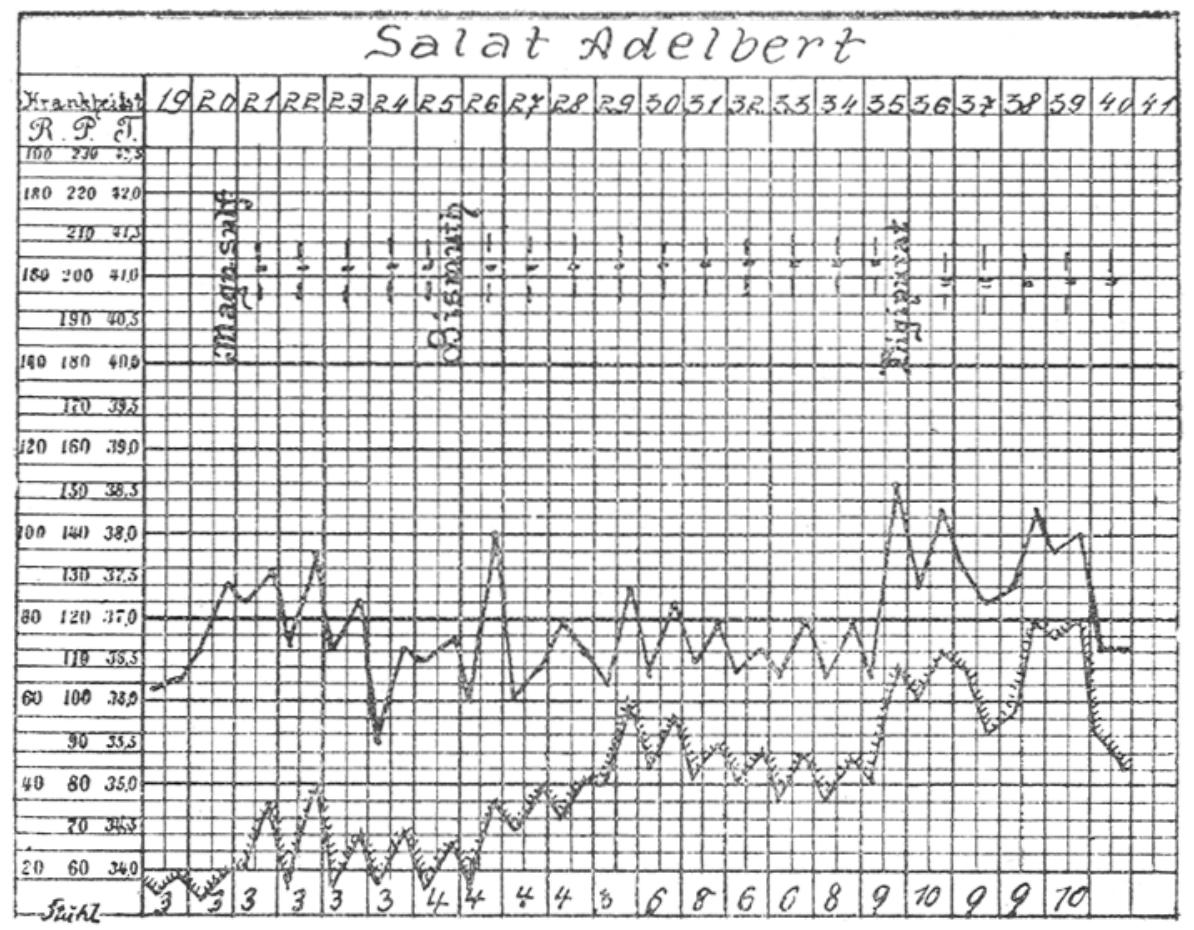

klein, 50. Zunge trocken, mit weissem Belag. An der Lunge links hinten rom Skapularand Perkussionsschall kürzer als rechts. Respiratorische Verschieblichkeit aufgehoben. Daselbst Reibegeräusube hörbar. Sonst äborall normaler Lungensehall. Herztöne leise. A bdomen etwas aufgetrieben, diffus druckempfindlich. Ueberall tympanitischer Darmschall. Oedeme an den Fussknöcheln. Stuhl flüssig, gelb, mit Scbleim und Blut untermischt, unverdaute Speisereste makroskopisch sichtbar. Urin: Eiweiss in Spuren, im Sediment keinerlei pathologische Bestandteile.

Rektoskopie: Sphinktertonus fehlt. Die ganze sichtbare Schleimhaut in eine mit Eiter und Schleim bedeckte Wundfläche umgewandelt, höher oben noch vereinzelte leicht baftende, diphtheritische Beläge. Die Rektoskopie wurde noch zweimal (am 15. 4. und 25. 4.) ausgeführt. Keinerlei Besserung, immer derselbe Befund.

Bakteriologischer Befund: Dys. Y.

Der Zustand des Patienten verschlimmert sich täglich. Vollkommener Appetitmangel, zeitweise Fiebersteigerungen. Die Oedeme nehmen trotz der Herzmittel und Einschränkung der Kochsalzzufuhr zu. Der Umfang des Abdomens nimmt zu.

Am 24. 4. konnte freie Flüssigkeit im Abdomen konstatiert werden. 
212 E. Fgan, P. Klemperer und R. Strisower, Zur Klinik asw. der Ruhr.

Unter Zeichen der Herzsehwäche und ständigem Kräfteverfall tritt der 'Tod am 30. 4. ein.

Sektionsbefund: Enteritis ulcerosa et crouposa recrudescens intestini crassi. Enteritis haemorrhagica partis infimi ilei. Synechia pleurae sin. Ascites, Anasarca.

\section{Literaturverzeichnis.}

1) Quincke, Med. Klinik. 1914. Nr. 4ð. - 2) Sternberg, Wiener klin. Wocbenschr. 1916. Nr. 40. - 3) Singer, Med. Klinik. 1911. Nr. 16. - 4) Derselbe, Oesterr. Sanitätsw. 1914. Beilage Nr. 46. - 5) Derselbe, Münch. med. Wochenschr. 1915. Nr. 6. -6) Matthes, Münch. med. Wochenschr. 1915. Nr. 45. - 7) Derselbe, Verhandl. in Warschau. 1915. - 8) Orth, Berliner klin. Wochenschrift. 1918. - 9) Löhlein, Med. Klinik. 1917. - 10) Galambos, Wiener klin. Wochenschr. 1918. S. 531. - 11) Strisower, Wiener klim. Wochenschr. 1916. S. 1441. - 12) Weltmann, Wiener klin. Wochenschr. 1916. S. 877. - 13) Rumpel und Knack, Deutsche med. Wochenschr. 1916. Nr. 44-47. - 14) Porges, Beibl. z. Mitt. d. Ges. f. inn. Med. u. Kinderheilk. 1915. S. 81. - 15) Ka uffmann und Schmidt, Münch. med. Wochenschr. 1917. S. 753. - 16) Jakob, Münch. med. Wocbenscbr. 1917. S. 125. - 17) Pribram, Zentralbl. f. Bakt. 1917. Bd. 80. II. $1-3$. 